\title{
MODELLING AIR QUALITY IN STREET CANYONS: A REVIEW
}

\author{
Sotiris Vardoulakis ${ }^{\mathrm{a}, \mathrm{c}}$, Bernard E.A. Fisher ${ }^{\mathrm{b}}$, Koulis Pericleous ${ }^{\mathrm{a},{ }^{*}}$, Norbert Gonzalez-Flesca ${ }^{\mathrm{c}}$ \\ "School of Computing and Mathematical Sciences, University of Greenwich, Maritime Greenwich University Campus, \\ 30 Park Row, London SE10 9LS, UK \\ "National Centre for Risk Analysis \& Options Appraisal, Environment Agency, Kings Meadow House, Kings Meadow \\ Road, Reading RGI 8DG, UK \\ 'Institut Nutional de l'Environnement Industriel et des Risques (INERIS), Parc Technologique ALATA, BP 2, 60550 \\ Verneuil-en-Halatte, France
}

\begin{abstract}
High pollution levels have been often observed in urban street canyons due to the increased traffic emissions and reduced natural ventilation. Microscale dispersion models with different levels of sophistication may be used to assess urban air quality and support decision making for pollution control strategies and traffic planning. Mathematical models calculate pollutant concentrations by solving either analytically a simplified set of parametric equations or numerically a set of differential equations that describe in detail wind flow and pollutant dispersion. Street canyon models, which might also include simplified photochemistry and particle deposition-resuspension algorithms, are often nested within larger-scale urban dispersion codes. Reduced-scale physical models in wind tunnels may also be used for investigating atmospheric processes within urban canyons and validating mathematical models.

A range of monitoring techniques is used to measure pollutant concentrations in urban streets. Point measurement methods (continuous monitoring, passive and active pre-concentration sampling, grab sampling) are available for gaseous pollutants. A number of sampling techniques (mainly based on filtration and impaction) can be used to obtain mass concentration, size distribution and chemical composition of particles. A combination of different sampling monitoring techniques is often adopted in experimental studies. Relatively simple mathematical models have usually been used in association with field measurements to obtain and interpret time series of pollutant concentrations at a limited number of receptor locations in street canyons. On the other hand, sophisticated numerical codes have often been applied in combination with wind tunnel and/or field data to simulate small-scale dispersion within the urban canopy.
\end{abstract}

Keywords: Urban environment; Air pollution; Street canyon; Dispersion models; Computational Fluid Dynamics (CFD); Wind flow regimes; Traffic emissions

*Corresponding author: Professor K. Pericleous

E-mail: k.pericleous@greenwich.ac.uk, Tel: +44 (0) 208 3318732, Fax: +44 (0) 2083318695

\section{Introduction}

\subsection{Urhen cuir quetily und traffic}

Urban air pollution was originally considered as a local problem mainly associated with space heating and industrial emissions, which are now controllable to a great extent. Despite significant improvements in fuel and engine technology, present day urban environments are mostly dominated by traffic emissions (Fenger, 1999; Colvile et al., 2001). It is now generally recognised that many of the substances directly emitted by vehicles in the ambient air or indirectly produced through photochemical reactions represent a serious hazard for human health (Hoek et al., 2000; Nyberg et al., 2000; Dab et al., 2001).

The main traffic-related pollutants are $\mathrm{CO}, \mathrm{NO}_{\mathrm{x}}$, hydrocarbons, and particles. $\mathrm{CO}$ is an imperfect fuel combustion product. Combustion also produces a mixture of $\mathrm{NO}_{2}$ and $\mathrm{NO}$, of which more than $90 \%$ is in the form of NO. A wide range of unburned and chemically transformed hydrocarbons (e.g. benzene, toluene, ethane, ethylene, pentane, etc.) is emitted by motor vehicles through a number of different processes (e.g. evaporation, fuel tank displacement, oil seep, etc.). Finally, particles of condensed carbonaceous material are emitted mainly by diesel and purely maintained petrol vehicles. 
Atmospheric pollutants are responsible for both acute and chronic effects on human health (WHO, 2000). CO is an asphyxiating pollutant that reduces the ability of blood to carry oxygen to the different organs (Burnett et al., 1998). Therefore, short-term exposure to high $\mathrm{CO}$ concentrations might cause an acute health impact. On the other hand, pollutants like benzene have an accumulative effect on human health. Long-term exposure to high benzene levels increases the risk for an individual to suffer from cancer (Cicolella, 1997). Furthermore, there are gases like $\mathrm{NO}_{2}$ that are responsible for both short- and long-term health effects. Depending on the effects related to each substance, atmospheric pollutants are regulated with respect to different exposure times. For example, in the European air quality guidelines, standards are set for benzene as one year averages, for $\mathrm{CO}$ as eight hour averages, and for $\mathrm{NO}_{2}$ as both one hour and one year averages (European Commission, 1999; 2000).

Particulate matter with aerodynamic diameter below $10 \mu \mathrm{m}\left(\mathrm{PM}_{10}\right)$ and especially the finer fraction with aerodynamic diameter below $2.5 \mu \mathrm{m}\left(\mathrm{PM}_{2,5}\right)$ was found to associate with increased daily mortality and asthma (Dockery and Pope, 1994; Anderson at al. 1992; Harrison and Yin, 2000). Nevertheless, current European legislation addresses only total $\mathrm{PM}_{10}$ as 24-hour and one year averages, while U.S. legislation regulates both $\mathrm{PM}_{10}$ and $\mathrm{PM}_{2.5}$ as three year averages (EPA, 1996).

Although roadside concentrations differ significantly from background levels, all outdoor environments are subject to the same regulatory standards for ambient air quality. This is due to the assumption that pollutant concentrations observed at a single or a few permanent monitoring stations within a city are representative of the exposure of the entire urban population.

In urban environments and especially in those areas where population and traffic density are relatively high, human exposure to hazardous substances is expected to be significantly increased. This is often the case near busy traffic axis in city centres. where urban topography and microclimate may contribute to the creation of poor air dispersion conditions giving rise to contamination hotspots. High pollution levels have been observed in street canyons, which is a term frequently used for urban streets flanked by buildings on both sides. Within these streets, pedestrians, cyclists, drivers and residents are likely to be exposed to pollutant concentrations exceeding current air quality standards.

\subsection{Air quality monitoring}

Nowadays, automated monitoring networks operate in many European cities providing detailed air quality information on a regular basis. There are several techniques available for monitoring gaseous pollutants (e.g. continuous monitoring using standard gas analysers, diffusive and pumped sampling using tubes filled with an appropriate adsorbent, grab sampling using canisters) and particulate matter (e.g. filtration and impaction). Each one of them can be associated with a number of advantages and disadvantages that make it suitable or not for a specific application.

The response time, which is the time over which the sample is taken, is one of the major factors that determine the suitability of a method. Standard gas analysers are sufficiently sensitive and fast to give real time (i.e. typical response time: $1-2 \mathrm{~min}$ ) measurements of $\mathrm{CO}, \mathrm{NO}_{\mathrm{x}}$ and $\mathrm{O}_{3}$ concentrations. The results can be then averaged over short time periods and compared to the regulatory standards.

Diffusive samplers have a relatively long response time (e.g. typically from one/two days to one/two weeks), which makes them less suitable for observing atmospheric pollutants responsible for short-term health effects. On the other hand, long response times might be preferable when sampling substances like benzene, whose impact on human health is due to cumulative exposure. In these cases, peak concentrations are of minor concern and therefore diffusive samplers appear to be the ideal choice (Cocheo et al., 2000; Skov et al., 2001). Furthermore, diffusive samplers are portable devices and do not need electrical power supply, which makes them very suitable for spatial distribution measurements (e.g. vertical profiles within canyons), air quality mapping, personal exposure studies, and detection of long-term pollution trends

The total number of air quality monitoring stations or sampling locations within a city is limited by practical constraints. Since pollutant concentrations might vary with a factor of 5 from a street canyon to an urban background area (Palmgren and Kemp, 1999), the selection of monitoring/sampling locations becomes fundamental. In addition, one should be cautious when comparing absolute values from different cities. The data are often based on one or few monitoring stations placed at critical sites and thus represent microenvironments rather than large urban areas (Fenger, 1999). In general, monitoring stations and/or samplers should be located near places of expected air pollution hotspots, but also must be reasonable with respect to population exposure over the averaging times associated with the regulatory values. 
Permanent air quality stations within a city may be classified into two broad categories: (a) the roadside and (b) the urban background stations. Roadside stations are usually located on the pavement of busy streets, avenues or intersections, within few meters distance from the roadway and with their sampling head at $1.5-3 \mathrm{~m}$ height above ground. On the other hand, background stations are placed in parks or other urban locations away from road traffic.

\subsection{Air yuality modelling}

The impact of air pollution on urban climates has become an important research issue (Georgii, 1969; Oke, 1988; Bitan, 1992), leading to numerous modelling studies related to the influence of buildings and other urban structures on pollutant accumulation/dissipation patterns. The main features of pollutant dispersion within urban canyons are well understood through the pioneering work of Johnson et al. (1973), Dabberdt et al. (1973), Hotchkiss and Harlow (1973), Nicholson (1975). Yamartino and Wiegand (1986) and others.

Dispersion models are now widely used for assessing roadside air quality by providing predictions of present and future air pollution levels as well as temporal and spatial variations (Sharma and Khare, 2001). When used in a knowledgeable way. they can be very useful in giving insights into the physical and chemical processes that govern the dispersion and transformation of atmospheric pollutants. This article provides an overview of modelling techniques and available software for assessing air quality in street canyons. In this framework. relevant experimental and theoretical studies are also briefly discussed.

\section{Street canyon characteristics}

\subsection{Camon geometry}

The term street canyon ideally refers to a relatively narrow street with buildings lined up continuously along both sides (Nicholson. 1975). However, the same term has been used to refer to larger streets, also called avenue canyons. In the real world. a broader definition of the term has been applied, including urban streets that are not necessarily flanked by buildings continuously on both sides, allowing thus for some openings on the walls of the canyon.

The dimensions of a street canyon are usually expressed by its aspect ratio, which is the height $(H)$ of the canyon divided by the width (ii). A canyon might be called regular, if it has an aspect ratio of approximately equal to 1 and no major openings on the walls. An avenue canyon may have an aspect ratio below 0.5 , while a value of 2 may be representative of a deep canyon. Finally, the length $(L)$ of the canyon usually expresses the road distance between two major intersections. subdividing street canyons into short $(L / H \approx 3)$, medium $(L / H \approx 5)$, and long canyons $(L / H \approx 7)$. Urban streets might be also classified in symmetric (or even) canyons, if the buildings flanking the street have approximately the same height, or casymmetric, if there are significant differences in building height.

\subsection{Wind flow}

The climate of street canyons is primarily controlled by the micro-meteorological effects of urban geometry rather than the mesoscale forces controlling the climate of the boundary layer (Hunter et al., 1992). A clear distinction should be made between the synoptic above roof-top wind conditions and the local wind flow within the cavity of the canyon (Fig. 1). Depending on the synoptic wind (or free-stream velocity), three main dispersion conditions can be identified: (i) low wind conditions, for synoptic winds lower than $1.5 \mathrm{~m} / \mathrm{s}$, (ii) perpendicular or near-perpendicular flow for synoptic winds over $1.5 \mathrm{~m} / \mathrm{s}$ blowing at an angle of more than $30^{\circ}$ to the canyon axes, and (iii) parallel or near-parallel flow for winds over $1.5 \mathrm{~m} / \mathrm{s}$ blowing from all other directions. In the case of perpendicular flow, the upwind side of the canyon is usually called leeward, and the downwind windward.

The emphasis has often been on the two-dimensional nature of the flow, studying vertical cross-sections at mid-canyon level. When the above roof flow is perpendicular to the canyon and the wind speed is greater than 1.5 to $2 \mathrm{~m} / \mathrm{s}$, flow may be described in terms of three regimes, depending on the dimensions of the street (Oke, 1988) (Fig. 2): (a) isolated roughness flow, (b) wake interference flow, and (c) skimming flow. For wide canyons $(H / W<0.3)$, the buildings are well spaced and act essentially as isolated roughness elements, since the air travels a sufficient distance downwind of the first building before encountering the next obstacle. As buildings become more closely spaced $(H / W \approx 0.5)$, the disturbed air flow has insufficient distance to readjust before encountering the downwind building, resulting in wake interference flow. In the case of regular canyons $(H / W \approx 1)$, the bulk of the synoptic flow skims over the canyon producing the skimming flow, which is characterised by the formation of a single vortex within the canyon (Hunter et al., 1992). 
From a three-dimensional point of view, a reflection of the wind off the windward wall of the canyon should be ideally observed in the case of skimming flow (Nakamura and Oke, 1988; Johnson and Hunter, 1999). For oblique roof-level winds, this reflection may induce a spiral wind flow through the canyon. Other complex channelling effects might be produced for winds parallel to the street axis. Additional low pressure areas and wind circulation is created near intersections. resulting in horizontal corner vortices. In relatively short canyons, corner vortices might be strong enough to inhibit a stable vortex perpendicular to the street in the mid-section. This ventilation effect fades with increasing street length (Theurer, 1999).

The strength of the wind vortices inside the canyon mainly depends on wind speed at roof-top level. However, the local wind flow is also affected by the mechanical turbulence induced by moving vehicles (Eskridge and Rao, 1986) or created near urban roughness elements within the street (e.g. trees, kiosks, balconies, slanted building roofs, etc.) (Hoydysh and Dabberdt. 1994: Theurer. 1999). Furthermore, the shape and strength of the wind vortices might be also affected by the atmospheric stability and other thermal effects induced by the differential heating of the walls and/or the bottom of the canyon (Sini et al., 1996; Kim and Baik, 2001).

In relatively deep canyons ( $H / W>1.3$ ), the main wind vortex is usually displaced towards the upper part of the cavity, with almost stagnant air below (DePaul and Shieh, 1986). As the aspect ratio increases $(H / W \approx 2)$, a weak counterrotating secondary vortex may be observed at street level (Pavageau et al., 1996). For even higher aspect ratios $(H / W \approx 3)$, a thild weak vortex might be also formed (Jeong and Andrews, 2002). In most cases, small week vortices occupy the bottom side corners of the canyon.

Depending on the wind direction, asymmetric canyons may be sub-divided into two categories: (i) step-up canyons, when the down-wind building is higher than the up-wind building, and (ii) step-down canyons, when the down-wind building is lower than the up-wind building. In these cases, mid-section wind vortices might be displaced or reversed within the cavity.

\subsection{Pollutant dispersion}

The dispersion of gaseous pollutants in a street canyon depends generally on the rate at which the street exchanges air vertically with the above-roof level atmosphere and laterally with connecting streets (Riain et al., 1998). Skimming flow, a feature of regular canyons, provides minimal ventilation of the canyon and is relatively ineffective in removing pollutants (Hunter et al., 1992). Field measurements (DePaul and Sheih, 1985, Qin and Kot, 1993) show increased concentrations of traffic-related pollutants on the leeward side of the canyon, and decreasing concentrations along with height above the ground on both sides of the street. The increased leeward concentrations are due to the accumulation of pollutants locally advected by the large wind vortex that covers most of the canyon. Minor pollution hotspots might be also created in small cavities where additional recirculation phenomena can take place.

Street-level cross-road gradients observed in wind tunnel experiments (Hoydysh and Dabberdt, 1988) for perpendicular wind conditions indicate that concentrations are generally a factor of two greater for the leeward than for the windward side, except for step-down canyons where windward concentrations are slightly greater than leeward. Concentrations are generally lower in the step-up canyons relative to the even and step-down notches.

Flow visualisation experiments have shown that the rotation of the main wind vortex in the canyon is periodically interrupted (Hoydysh and Dabberdt, 1988; Pavageau et al., 1996). As a result, the pollutants trapped within this vortex are periodically flushed out of the canyon, a phenomenon known as canyon breathing (Scaperdas, 2000). In relatively long canyons without connecting streets, maximum street-level concentrations are more likely to occur when the synoptic wind is parallel to the street axis. In that case, the accumulation of emissions along the line source outweighs the ventilation induced by the parallel winds (Soulhac et al., 1999; Dabberdt and Hoydysh, 1991).

Low synoptic winds create a well-known meteorological situation that favours air pollution built-up in urban areas (Qin and Kot, 1993; Vignati et al., 1996; Jones et al. 2000). When the synoptic wind speed is below $1.5 \mathrm{~m} / \mathrm{s}$, the wind vortex within the canyon disappears and the air stagnates in the street. In that case, the mechanical turbulence induced by moving vehicle as well as the atmospheric stability conditions might play a significant role in the dispersion of trafficgenerated pollutants.

Fine and especially ultra-fine particles are expected to disperse in the air like gases. The larger-sized particles, however, are greatly affected by gravity and thus have a shorter residence time in the air (Chan and Kwok, 2000). For this reason, 
the coarse fraction of the total suspended particles (TSP) exhibits larger vertical concentration gradients than those usually observed for gases or fine particles.

\subsection{Pollutunt transformation}

Due to the very short distances between sources and receptors, only very fast chemical reactions have a significant influence on the measured concentrations within street canyons (Berkowicz et al., 1997). For this reason, most trafficrelated pollutants (e.g. $\mathrm{CO}$ and hydrocarbons) can be considered as practically inert species within these distances. This is not the case either for $\mathrm{NO}_{2}$, which dissociates extremely fast in the presence of light, or for $\mathrm{NO}$, which also reacts very fast with $\mathrm{O}_{3}$. The time scales of these chemical reactions are of the order of tens of seconds, thus comparable with residence times of the pollutants in a street canyon.

It is expected that the relationship between relatively stable chemical species emitted by vehicles would not vary significantly within urban streets. This is very helpful for epidemiological studies, because a single or only few indicators can be identified for assessing population exposure to traffic-related air pollution (Kingham et al., 2000).

\subsection{Population exposure}

From a population exposure point of view, air quality in street canyons is of a major importance, since the highest pollution levels and the larger targets of impact are often concentrated in this kind of streets. The so-called canyon effect (i.e. the reduced natural ventilation in urban streets) results in greater health impacts (e.g. indicated by an increased number of respiratory hospital admissions) and damage costs for the exposed population (Spadaro and Rabl, 2001).

Personal exposure can be calculated as the product of the pollutant concentration and time spent in a specific microenironment, which is defined as a confined space (e.g. bedroom, office, car, parking, pavement, etc.) where pollutant concentrations are assumed to be uniform (Colls and Micallef. 1997). The total personal exposure will be then the sum of all such products. However, the assumption of spatial uniformity of air pollution might be erroneous for certain microenviromments like street canyons, where strong spatial concentration gradients are often observed. In these cases. exposure calculations should be refined by subdividing microenvironments into sub-microenvironments, taking into account pollution hot spots and refined human breathing zones (e.g. for residents, pedestrians, cyclists, drivers, etc.).

Relatively few examples of this approach can be found in literature. In a study attempting to quantify residential exposure to exhaust gases in Oslo (Larssen et al., 1993), a correction coefficient was introduced to account for changes in ambient concentrations with height over street level. Other authors (Croxford and Penn, 1998) have suggested that a side of the street factor should be introduced if the prevailing wind direction is perpendicular or near-perpendicular to the street axis

\section{Street canyon modelling}

There is a plethora of dispersion models specially developed for or simply used in street canyon applications. They can be useful in air quality and traffic management, urban planning, interpretation of monitoring data, pollution forecasting, human exposure studies, etc. Although there are no clear-cut distinctions between different categories, models might be classified into groups according to their physical (e.g. reduced-scale) or mathematical principles (e.g. box, Gaussian, CFD) and their level of sophistication (e.g. screening, semi-empirical, numerical). Some of these (often overlapping) categories and corresponding models are presented in Table 1.

\subsection{Parametric models}

\subsubsection{Gicussican plume moctels}

These are sets of equations describing the three-dimensional concentration field generated usually by a point source. They assume that the concentrations from a continuously emitting source are proportional to the emission rate, inversely proportional to the wind speed, and that the time averaged pollutant concentrations horizontally and vertically are well described by Gaussian (i.e. bell-shaped) distributions (Boubel et al., 1994). In its simplest form, the Gaussian plume model assumes that there are no chemical or removal processes taking place and that pollutant material reaching the ground or the top of the mixing layer as the plume grows is reflected back towards the plume centreline. 
Gaussian plumermodels rely on the appropriate selection of the plume spread sigma functions (in both the horizontal and vertical sense), which are generally expressed in terms of Pasquill atmospheric stability classes or Monin-Obukhov similarity theory parameters (Zannetti, 1990). Models using the latter approach dispose of height dependent sigma functions and are known as second generation Gaussian plume models (Carruthers et al., 1994).

Apart from industrial applications (i.e. point sources), specially designed Gaussian plume models can be used to calculate pollutant concentrations over urban agglomerations (i.e. area sources) and in the vicinity of highways (i.e. line sources). Gaussian models are not directly applicable to small-scale dispersion within the urban canopy, since they treat buildings and other obstacles only via a surface roughness parameterisation (Scaperdas, 2000). Nevertheless, in some cases, they include specialised modules for street canyons. This is the case of ADMS-Urban (Owen et al., 1999), a second generation urban-scale dispersion model that includes a street canyon module nested within the core Gaussian code.

\subsubsection{CALINEA}

CALINE4, the latest version of the CALINE series of pollutant dispersion models, is one of the most validated models available for assessing the impact of vehicle traffic on roadside air quality (Benson, 1984). It has been widely used in scientific and engineering applications mainly concerning highway development and management (Jones et al, 2000). Although CALINE4 is able to handle canyon or intersection situations, it has been used in relatively few urban air quality studies.

The model uses Gaussian plume theory to simulate the dispersion of pollutants emitted from a line source. This is divided in a series of elements, which are modelled as equivalent finite line sources located normal to the wind direction. The region directly over the road. called the mixing zone, is treated as a zone of uniform emission and turbulence. Within the mixing zone. vehicle induced turbulence (both mechanical and thermal) is taken into account (Benson, 1992).

The street canyon algorithm devised by Turner (1970) computes the effect of single or multiple horizontal reflections of the plume on the walls of the canyon. In this case, the road axis and the wind velocity are assumed to be parallel to the horizontal topographic boundary (i.e. the walls of the canyon), resulting in equal concentrations on both sides of the street.

\subsubsection{TNO and CAR}

TNO-Traffic is a Gaussian plume-type model that describes the dispersion of traffic exhausts (Eerens et al., 1993). It is based on an extensive programme of wind tunnel experiments which covered a great number of different street configurations, including urban canyons and intersections (van den Hout et al., 1994). In this model, the traffic is represented by line sources divided into series of small point sources.

CAR (or CAR-International) is a simplified version of the same model, in which only the most representative street configurations were categorised (den Boeft et al., 1996). For each street type (e.g. highway, urban road, etc.) a sourcereceptor relationship is specified as a function of the distance between the receptor and the street axis. CAR uses annual average wind speeds and assumes that there is no prevailing wind direction. Thus, the user obtains the same yearly averages and percentiles on either side of the street. In all cases, the effect of trees and moving vehicles on street-level wind velocity is taken into account. This model should not be confused with CAR-FMI (Härkönen et al., 1995), which is a Gaussian line source model for calculating pollution from road networks.

\section{I.A. STREET-SRI}

Johnson et al. (1973) used a single box model, together with some simplified assumptions concerning initial dispersion and car induced turbulence, to derive a street canyon sub-model usually called STREET or SRI (e.g. Stanford Research Institute), which formed part of a multipurpose urban diffusion model for inert pollutants (APRAC). It is based on the assumption that concentrations of the pollutant occurring on the roadside consist of two components, the urban background concentration and the concentration component due to vehicle emissions generated within the specific street. Then, it calculates pollutant concentrations on both sides of the street, taking into account the height and distance of the simulated receptor from the kerb.

On the leeward side of the canyon, concentrations are assumed to be inversely proportional to the distance between the line source and the receptor point. On the windward side, the original expression given by Johnson et al. (1973) was revised by Dabberdt et al. (1973) to account for vertical decrease of concentrations due to entrainment of fresh air 
through the top of the canyon. For parallel or near-parallel synoptic winds, the average of the leeward and windward values might give the pollutant concentration on both sides of the street, although the model is not specifically designed for this situation. STREET-SRI was parameterised using data from a regular street canyon and for this reason it might need re-calibration before being applied to other canyon geometries.

\subsection{5. $C P B M$}

The Canyon Plume Box Model (Yamartino and Wiegand, 1986) combines a Gaussian plume model for the direct impact of pollutants emitted in the street, with a box model that accounts for the additional impact of pollutants trapped within the wind vortex formed inside the canyon. The wind flow in the canyon is reproduced using the methodology proposed by Hotchkiss and Harlow (1973) for the two transverse components of the wind velocity and a logarithmic expression for the longitudinal component. An empirical model that takes into account wind generated turbulence as well as thermal effects induced by solar radiation and moving vehicles is used to calculate the turbulent sigma parameters representing the standard deviation of flow velocities about the mean flow.

The plume generated inside the canyon is divided into three segments, which are assumed to follow straight line trajectories and disperse according to Gaussian plume formulas. The impact resulting from the recirculation component is calculated from the consideration of the mass budget inside the canyon. On the leeward side of the street, the total impact is calculated by adding the direct plume to the recirculated fraction. On the windward side, where the only contribution arises from the recirculation component, the dilution of the concentrations due to the entrainment of fresh air is also taken into account. For winds parallel to the street axis or for very low wind speeds, a simpler plume model is used.

\subsubsection{OSP.1/ and AEOLIUS}

AEOLIUS (Buckland, 1998) is based on concepts and techniques previously used for the development of the Operational Street Pollution Model (Hertel and Berkowicz, 1989a), which was evolved from the CPBM. AEOLIUS and OSPM are semi-empirical models that calculate concentrations of exhaust gases on both sides of a canyon assuming three different contributions: (a) the contribution from the direct flow of pollutants from the source to the receptor, (b) the recirculation component due to the flow of pollutants around the vortex generated within the recirculation zone of the canyon, and (c) the urban background contribution. A Gaussian plume algorithm is used for the calculation of the direct contribution and a simple box model for deriving the recirculation component.

The vortex is formed inside the canyon, if the synoptic wind is not parallel to the street axis. The length of the vortex (along the wind direction) is 2 times the upwind building height. For synoptic winds below $2 \mathrm{~m} / \mathrm{s}$, the length of the vortex decreases with the wind speed (Berkowicz, 2000a). The width of the recirculation zone cannot exceed the width of the canyon in any case. The relation between street-and roof-level winds in the canyon is given by a logarithmic relationship that takes into account the surface roughness length, the height of initial dispersion of car exhausts and the synoptic wind direction.

On the leeward side of the street, concentrations are calculated as the sum of the direct and recirculation contributions, while on the windward side only the direct contribution of emissions generated outside the recirculation zone are taken into account. If the recirculation zone extends throughout the whole canyon, then the windward concentrations are calculated from only the recirculation component. For near-parallel flow, emissions from outside the recirculation zone may contribute to the leeward concentrations. When the wind speed is near zero or parallel to the street axis, the concentrations on both sides of the canyon become equal. Finally, the mechanical turbulence in the street due to the wind and vehicle traffic is empirically derived.

AEOLIUS (the Full version) is based on the same formulation as OSPM. Nevertheless, some discrepancies between predictions from the two models cannot be excluded, due to differences in coding, parameterisation and data preprocessing techniques. There are also two screening versions of AEOLIUS, namely AEOLIUS Screen and AEOLIUSQ Emission, made available by the U.K Met Office.

\subsubsection{Receptor models}

The models described in the previous sections may be also defined as source-oriented models. Such models rely on the use of best available emission estimates and meteorological data to predict pollutant concentrations at various roadside locations. An alternative approach is the receptor-oriented modelling, which is based on the detailed analysis of the pollutant collected at one or more monitoring sites. This analysis, also called source apportionment or chemical mass 
balance (Gordon et al., 1984), attempts to determine which sources contributed to the concentration measured at the receptor point. If the pollutant of interest is chemically inert (e.g. $\mathrm{CO}$ ), there is no way to distinguish between different sources. But if the pollutant consists of a variety of chemical species (e.g. particulate matter), then from its chemical composition one can make inferences about the sources.

Receptor-oriented models, such as the Constrained Physical Receptor Model (CPRM) (Wåhlin et al., 2001), are mostly used to test the predictions made by source-oriented models as well as the accuracy of the emission estimates that are used in them (Karim and Ohno, 2000).

\subsection{CFD models}

Computational Fluid Dynamics (CFD) modelling is a general term used to describe the analysis of systems involving fluid flow. heat transfer and associated phenomena (e.g. chemical reactions) by means of sophisticated computer-based numerical methods. It is a powerful modelling technique spanning a wide range of industrial and more recently environmental and biomedical applications (Gosman, 1999).

What distinguishes CFD from other Eulerian models is their capability to deal with very complex shaped walls and other boundary conditions (e.g. in aircraft and automobile design) using flexible fine-scale grids. Furthermore, they include a more sophisticated treatment of turbulence, which makes them suitable for small-scale pollutant dispersion applications.

CFD codes are structured around numerical algorithms that can tackle fluid flow problems. In order to provide easy user access, most commercial CFD packages include sophisticated input and output interfaces. Hence, they contain three main elements: (I) The pre-processor, which serves to input problem parameters, generate the grid of the computational domain. select the physical and chemical phenomena that need to be treated, define the fluid properties, and finally specify the appropriate boundary conditions. (II) The solver, which first approximates numerically the unknown flow variables, then discretises the governing flow equations using these approximations, and finally solves the resulting system of algebraic equations. (III) The post-processor, which displays the grid and geometry of the domain, plots vectors (e.g. wind velocity) and contours (e.g. pollutant concentration) and may even provide animation facilities for dynamic result display.

\subsubsection{Phisical principles}

CFD modelling is based on the numerical solution of the governing fluid flow and dispersion equations, which are derived from basic conservation and transport principles: (a) the mass conservation (contimity) equation, (b) the three momentum conservation (Navier-Stokes) equations in $x, y, z$, and (c) the transport equation for pollutant concentration. The equations of state (obtained through the thermodynamic equilibrium assumption) and the Newtonian model of viscous stresses are also enlisted to close the system numerically. The initial and boundary conditions are specified by the user.

Furthermore, atmospheric turbulent processes need to be modelled. Existing turbulence models can be classified in two broad categories: (1) The classical models based on Reynolds Averaged Navier-Stokes (RANS) flow equations (e.g. the $k-\varepsilon$ model, which is by far the most used and validated); (II) the Large Eddy Simulation (LES) models, which are computationally very demanding and therefore mainly used in research applications (Versteeg and Malalasekera, 1995).

\subsubsection{Numerical principles}

There are three different streams of numerical solution techniques: finite difference, fine element, and spectral methods. The main differences between them are associated with the way in which the flow variables are approximated and with the discretisation processes. The finite volume method, which was originally developed as a special finite difference formulation, is now the most well established and thoroughly validated method (it is central to most popular CFD codes: PHOENICS. FLUENT, STAR-CD).

According to this method, the flow domain is divided into individual finite control volumes (or computational cells). The differential flow equations are then integrated over each cell in order to transform them into a set of approximated algebraic difference equations between all nodal points of the grid. An advantage of the finite volume method is that mass and momentum conservation is imposed at cell level, which ensures that the discretised form of the flow equations integrated over the entire domain is also conservative. 
An iterative approach is required for solving the system of algebraic difference equations resulting from the discretisation method. The most popular solution procedures are the TDMA, a line-by-line solver of the algebraic equations, and the SIMPLE algorithm. The Semi-Implicit Method for Pressure Linked Equations (SIMPLE), originally proposed by Patankar and Spalding (1972), is a predictor-corrector method. That means that velocities are predicted by solving the momentum conservation equations using the most recent estimate of the pressure field, and then the pressure field is corrected by using the imbalances in the mass conservation equations. The other conservation equations are then solved, and the procedure is iterated until reaching convergence (i.e. when the imbalance in all conservation equations reaches a sufficient low value).

\subsubsection{Applications and codes}

When pollutant dispersion is examined within a street canyon, the computational domain should be sufficiently extended to stabilise the air inflow and outflow through the geometrical boundaries of the area. The relief of the buildings (e.g. due to the presence of balconies) or the street (e.g. due to the presence of vegetation, parked cars, etc.) can be taken into account by introducing a roughness coefficient for each surface of the domain. The space discretisation is usually not uniform. since a higher resolution is required near the canyon walls and the roadway. Finally, fields of pollutant concentrations, wind velocity and other physical quantities (e.g. turbulent kinetic energy and eddy diffusivity) may be reproduced.

The commercially available general-purpose CFD codes PHOENICS, FLUENT, STAR-CD, CFX-TASCflow and Fluidyn-PANACHE have been used in a number of street canyon applications. Other numerical models like MERCURE (Carissimo et al.. 1995). CHENSI (Levi Alvares and Sini, 1992) and MISKAM (Eichhorn, 1995) were specially designed to simulate pollutant dispersion at local scale. MISKAM was used to create a database of numerical three-dimensional simulations that was integrated in a screening model called STREET (Petit et al., 2000). Furthermore, the street canyon module PROKAS-B, which forms part of the Gaussian urban scale model PROKAS-V, was also based on dimensionless concentrations calculated using a version of MISKAM. Finally, the microscale models MIMO and MITRAS were also specially designed for street canyon applications and nested within the mesoscale MEMO and METRAS, respectively (Ehrhard et al.. 2000).

\subsection{Reduced-scale models}

The reduced-scale (or physical) models are based on the principle that by reducing the geometrical scale of a given flow domain and adjusting the reference parameters (e.g. flow velocity), the original full-scale conditions can be reproduced. Reduced-scale modelling can be carried out in a wind tunnel or a water tank facility. Although wind tunnels have been more widely used for simulating pollutant dispersion than water tanks, the same principles and considerations apply to both the methods.

Three monitoring techniques may be involved in wind tunnel experiments: (a) flow visualisation, which helps to explore the range of possible flow and dispersion patterns obtained for different building arrangements, (b) tracer dispersion, which is used to quantify concentrations at receptor locations within the canyon, and (c) Laser Doppler Anemometry (LDA), which is used to study in more detail the patterns observed during flow visualisation experiments.

Although wind tunnel modelling involves a considerable simplification and idealisation of the real full-scale situation in terms of street geometry, meteorology, traffic flow and emissions, it can efficiently approximate real atmospheric conditions in urban streets. Furthermore, it allows isolating and studying separately each one of the phenomena involved in microscale pollutant dispersion. Wind tunnel measurements have been widely used for model development and validation (Baker and Hargreaves, 2001). However, differences between wind tunnel and full-scale experimental data should be carefully considered when validating numerical models (Schatzmann et al., 1999).

\subsection{Model requirements}

Dispersion model predictions are in most cases a function of meteorology, street geometry, receptor location, traffic volumes and emission factors. The acquisition and pre-processing of these data is an important part of any modelling study. since the performance of a model greatly depends on the quality of the inputs.

\subsubsection{Traffic dela}


Detailed traffic'information, including traffic volumes, fleet composition (e.g. ratio of light/heavy duty vehicles) and average vehicle speeds, is normally required for running street canyon models. Part of this information (e.g. traffic volumes and average vehicle speeds) might be obtained from automatic detectors permanently or temporarily operating in the street of interest. The vehicle fleet composition, however, is rarely available for a specific location and time period and for this reason has to be estimated from on site spot measurements. At least few manual traffic counts should be always taken to assure the quality of data obtained from automatic traffic networks.

\section{3.t.2. Emissions}

All street canyon models require vehicle emission factors (e.g. $\mathrm{g} / \mathrm{km}$ per single vehicle) or emission rates (e.g. $\mathrm{g} / \mathrm{km} \mathrm{per}$ hour) as input. although some operational models (e.g. CAR International) might include default emission factors for certain countries. In certain models (e.g. AEOLIUS), separate emission factors for small and large vehicles need to be specified. The emission rates in a street can be derived from the traffic volumes and the composite emission factors of the pollutants. A number of methodologies and models may be applied to determine the appropriate fleet-average emission factors.

The CORINAIR working group (sponsored by the European Commission) developed a methodology for calculating emissions, including appropriate emission factors, from road traffic (Eggleston et al., 1993). The methodology was transformed into the computer program COPERT (Ntziachristos and Samaras, 1997; 2000). The same methodology was adopted by ADEME (1998) to develop IMPACT, a road traffic emission model which quantifies fuel consumption and atmospheric releases of a specified vehicle fleet in a given year in France. Emissions are calculated for two vehicle operating modes: hot and cold start. The required input parameters are traffic composition, average vehicle speed, length and slope of the road segment of interest. In addition, the month of the year is used to estimate average ambient temperatures. which are further used for calculating evaporative and cold running emissions. The model provides default values for the average travelling distance and the fraction of this distance run with a cold engine in France.

The U.S. EPA has developed and regularly revised MOBILE, which is also a mobile source emission factor model. MOBILE distinguishes moving vehicles into three operating modes: cold start, hot stabilised and hot start. The model inputs include the vehicle miles travelled by each specified type of vehicle, ambient temperature, terrain altitude, calendar year: average vehicle speed, etc. Default values applying to the U.S. vehicle fleet are provided within the model. A related EPA model. PART5, can be used to calculate emission factors for particulate matter. In California, the Air Resources Board's EMFAC model is used in place of MOBILE.

An important aspect that differentiates MOBILE from COPERT is that the latter bases its assumptions on fuel sale statistics, while MOBILE assesses annual mileage accumulation rates by using data from traffic surveys. Other significant differences lie in the way the two models account for the effect of low ambient temperatures and cold start emissions (Zachariadis and Samaras, 1999). A detailed comparative analysis of MOBILE5a and COPERT was presented by Samaras and Zachariadis (1994).

The German MOBILEV emission model can also be used to calculate yearly or hourly average emissions for a single street or a street network using available information on emission factors, traffic mode, street characteristics and vehicle fleet composition. Congested traffic and cold start emissions are also taken into account. Casella Stanger in asociation with AEA Technology developed a spreadsheet model for $\mathrm{NO}_{\mathbf{x}}$ and $\mathrm{PM}_{10}$ emission factor on behalf of the U.K. Department of the Environment (DEFRA), to assist local authorities in the air quality review and assessment process. Finally, the protocol used by Buckland and Middleton (1999) can be applied for estimating composite emission factors for most regulated pollutants in the U.K. This methodology is based on predefined emission factors specific to each vehicle category. The fleet composition is then used to derive a composite emission factor for the road segment of interest.

Although this list of models is not exhaustive, it gives an idea of the existing emission calculation methodologies and the required inputs. It should be stressed that emission factors have to be regularly updated to reflect changes in fuel standards, vehicle fleet composition and engine technology (Stedman et al., 2001). It is generally recognised that emission factors represent one of the most important source of uncertainty in modelling traffic pollution (Kühlwein and Friedrich, 2000).

\subsubsection{Meleorological data}


The amount of required meteorological information for air quality modelling is proportional to the sophistication of the selected model. Simple models for screening applications (e.g. CAR and AEOLIUS Screen) only require the average wind speed over a period of time, assuming that there is no prevailing wind direction. Relatively more sophisticate street canyon models (e.g. OSPM and AEOLIUS Full) require time series of wind speed and direction for the dispersion calculations, ambient temperature and global radiation for the photochemistry algorithm, and (in some cases) atmospheric pressure for unit conversion. In addition to this information, CFD codes (e.g. PHOENICS) require certain specifications concerning atmospheric turbulence and wind profiles. Finally, Gaussian models (e.g. CALINE4) may need additional information on atmospheric stability and mixing height, although these parameters generally do not play an important role in pollutant dispersion within urban canyons. This is because the mechanical turbulence produced by building and vehicles outbalances the influence of the atmospheric turbulence (Leisen and Sobottka, 1980).

It should be remembered that meteorological data obtained simultaneously at different weather stations located within few kilometre distances from each other might differ significantly, especially for short averaging periods. When the first street canyon models were developed few decades ago, it was assumed that the local roof-top wind information needed as an input would not be generally available, and airport ten-meter wind data would have to be used. For this reason, empirical expressions relating airport and local winds were derived (Johnson et al., 1973). However, recent research studies have shown that model simulations carried out using airport winds generally produce lower and less accurate air quality predictions compared to those produced using local wind data (Manning et al., 2000).

\section{3.t. S. Street geometry}

Again, more sophisticated models require a larger amount of input information. Simple models may only need the height and the width of the canyon as input (e.g. AEOLIUS Screen), or just the type of the street and the distance between simulated receptor and road axis (e.g. CAR). Semi-empirical models (e.g. OSPM) may additionally require the length and the orientation of the canyon and allow for some gaps between the buildings. A surface roughness coefficient might be also provided by the user. Although there are both experimental and theoretical methods for estimating the roughness length of an urban surface (Pal Arya S., 1988), arbitrary values $(\approx 0.6 \mathrm{~m})$ are often used.

Relatively simple mathematical models are generally not able to capture the details of the urban canopy (e.g. trees, slanted building roofs, balconies, parked cars, etc.), which might have a significant influence in small-scale pollutant dispersion within street canyons (Gayev and Savory, 1999; Rafailidis, 2000). By contrast, CFD models are able to closely reproduce the details of the urban canopy, if the necessary input information is available. Four main types of boundary conditions imposed to the physical limits of the simulated area have to be specified: (a) the walls, (b) the inlets, (c) the outlets. and (d) the planes of symmetry (i.e normal velocities are set to zero at a symmetry boundary and the values of all other properties just outside the solution domain are equal to their values just inside the domain). Most commercial CFD codes provide the necessary graphical and numerical tools for treating complex street configurations, including fixed and moving obstacles (Theurer, 1999; Venetsanos et al., 2001).

\subsubsection{Background concentrations}

Even the simplest urban canyon models require a background pollution value as input, to account for the fraction of the pollutant that is not emitted within the simulated street. The urban background concentration can be defined in several ways. Ott and Eliassen (1973) suggested the existence of an urban CO background concentration as a relatively constant concentration that would be observed at a number of locations throughout the city, providing that the observer was at least 200 feet from the nearest street. Other authors have suggested the use of roof-top measurements as an estimate of the urban background levels. An alternative approach is to simulate the entire urban area using a larger scale model in order to determine background levels contributed by non-localised sources. The main disadvantage of this method is that it requires additional input data, which are subject to uncertainties (Cooper, 1987).

Berkowicz (2000b) developed a simple model for urban background pollution that can be used in combination with OSPM. ApSimon et al. (2001) adopted ADMS-Urban within the integrated assessment model USIAM to define contributions from different sources at different background receptor locations. CAR includes a simple algorithm for deriving urban background using the regional background (i.e. background due to distant sources) and the diameter of the built-up city area. Nevertheless, the commonest (and more reliable) modelling practice is to obtain background concentrations from measurements at urban locations that are not directly affected by local sources.

\subsection{Sipecial features}




\subsubsection{Deposition and resuspension}

The mass of total suspended particles (TSP) and $\mathrm{PM}_{10}$, usually measured in fixed monitoring stations, is dominated by the coarser fraction of airborne particulate matter. The $\mathrm{PM}_{10}$ fraction may be transported over long distances (Vignati et al. 1999). It is unlikely for an all-purpose street canyon model to be able to reproduce atmospheric aerosol concentrations measured on the kerbside, unless long range transport, local and regional non-traffic sources, relative humidity, deposition and resuspention processes are adequately taken into consideration.

The number of measured particles is dominated by the smaller fraction of $\mathrm{PM}_{2.5}$ known as ultra-fine particles (i.e. aerodynamic diameter $<100 \mathrm{~nm})$. Significant correlation at street level was observed between traffic-related gases $\left(\mathrm{NO}_{x}\right.$, $\mathrm{CO}$ ) and ultra-fine particle numbers detected in a street canyon in Copenhagen (Wăhlin et al, 2001), indicating that traffic was their major source in the urban air. Ultra-fine particles are generally expected to behave like inert gases within short distances from their sources. Therefore, their concentration may be successfully calculated using urban canyon models (e.g. OSPM) originally developed for gaseous pollutants (Le Bihan et al., 200l).

\subsubsection{Chemistry}

Simple street canyon models (e.g. STREET-SRI) may only calculate concentrations of passive compounds (e.g. CO). On the other hand. models that are used in regulatory applications need to take fast photochemical reactions into account in order to calculate $\mathrm{NO}_{\mathrm{x}}$ concentrations. OSPM uses a simplified chemistry algorithm to account for the transformation of reactive species (i.e. $\mathrm{NO}_{\mathrm{x}}$ and $\mathrm{O}_{\mathfrak{j}}$ ) inside a street canyon. AEOLIUS includes a subroutine that calculates statistically $\mathrm{NO}_{2}$ from $\mathrm{NO}$, concentrations by means of an empirical curve-fit formula derived from measurements in London (Derwent and Middleton. 1996). In that case, a maximum ratio is set to prevent the $\mathrm{NO}_{2}$ exceeding $25 \%$ of the $\mathrm{NO}_{\mathrm{x}}$ at high concentrations. CAR uses an empirical relationship derived from the more elaborated TNO model to calculate streetlevel $\mathrm{NO}_{2}$ concentrations, depending on $\mathrm{O}_{3}$ levels, the fraction of total $\mathrm{NO}_{4}$ directly emitted as $\mathrm{NO}_{2}$, and the type of the street. Finally. CALINE4 includes the Discrete Parcel Model for $\mathrm{NO}_{\mathrm{x}}$ chemistry.

General-purpose CFD models are only able to provide concentrations of inert pollutants, since they do not usually take photochemistry into account. However, specially designed microscale models may combine CFD codes with simplified chemistry algorithms. For example, WinMISKAM adds to MISKAM a simple NO-NO2 conversion model. A simple photochemistry algorithm is also implemented in the street and neighbourhood scale MICRO-CALGRID model, which is linked with MISKAM, as an alternative to the full chemistry scheme implemented in the urban scale CALGRID model (Stern and Yamartino. 2001).

\subsubsection{Vertical profiles}

Relatively simple street canyon models (e.g. AEOLIUS, CAR, etc.) only calculate street-level pollutant concentrations, without giving the user the possibility of choosing the height of the simulated receptors. It has been suggested by several authors (Capannelli et al., 1977; Huang, 1979; Dabberdt and Hoydysh, 1991; Zoumakis, 1995; Vardoulakis, 2002a) that the vertical concentration profiles in a street canyon generally satisfy a law of exponential reduction with height, although more complex patterns depending on the side of the street, the distance from the walls, and the small-scale features of the buildings may be also observed (Kastner-Klein and Plate, 1999; Jicha et al., 2000). The exponential redaction law might not be applicable to traffic-related substances with very short chemical lifetime (e.g. NO, NO$)$. It has been experimentally demonstrated (Väkevä et al., 1999) that $\mathrm{NO}_{2}$ concentrations may even increase with height within a street canyon, when the weather conditions favour photochemical activity.

\section{Street canyon studies}

Several modelling and experimental field studies aiming to establish pollutant dispersion and transformation patterns within street canyons have been carried out in the past. Depending on their objectives, different modelling and monitoring techniques have been adopted. Some of these studies were purely experimental, which means that they were exclusively based on full- and/or reduced-scale measurements. At the other end of the spectrum, some purely theoretical studies mainly focusing on the investigation of different wind flow and pollutant dispersion regimes using mathematical models can be also found in the literature. 
Most commonly, street canyon studies combine both mathematical modelling and experimental work. They may follow two different research approaches. The first one is based on the use of relatively simple parametric models and data obtained from field and/or wind tunnel experiments. Usually, the objective of this kind of studies is to determine the spatial and temporal variability of roadside air pollution, validate operational models, estimate population exposure, etc. The second approach is based on the use of more sophisticated CFD models and experimental data from wind tunnel and/or field measurements. The objective of these studies is usually to obtain a detailed description of the wind and concentration fields within the urban canopy under well-defined dispersion conditions.

Recently, the European research network TRAPOS (Optimisation of Modelling Methods for Traffic Pollution in Streets) gave new insights in a number of street canyon related issues: (a) the influence of moving vehicles on pollutant dispersion and turbulence in urban streets (Kastner-Klein et al., 2000 and 2001; Vachon et al., 2001); (b) the thermal effects on flow and dispersion within street canyons especially under low wind conditions (Kovar-Panskus et al., 200 la; Louka et al.. 2001); (c) the sensitivity of flow and turbulence characteristics to the geometry of the street and its surroundings (Kovar-Panskus et al., 2001b; Kastner-Klein and Rotach, 2001; Leitl et al., 2001; Chauvet et al., 2001); (d) the dispersion and transformation of traffic-related particles (Le Bihan et al., 2001; Wåhlin et al., 2001). TRAPOS included field and wind tunnel measurements, as well as mathematical simulations carried out with advanced numerical (MISKAM. CHENSI, MIMO, CFX-TASCflow) and a simpler parametric model (OSPM). A significant part of the work within the network was devoted to the inter-comparison and evaluation of these models (Sahm et al., 2001; Ketzel et al., 200 ) (Fig. 3). In the following sections, representative studies covering all aspects of street canyon research are briefly discussed.

\subsection{Full-scale experiments}

DePaul and Sheih $(1985 ; 1986)$ carried out a tracer gas $\left(\mathrm{SF}_{6}\right)$ experiment in an urban street canyon in Chicago (U.S.A.) in order to obtain measurements of pollutant retention times and resuiting concentrations within the canyon. The mean wind velocities were determined by analysing trajectories of air balloons that were released in the street. Nakamura and Oke (1988) studied the climate of urban canyons using field observations of wind and temperature from a street canyon in Kyoto (Japan). These observations were used to derive simple algorithms relating the above roof-level to the withincanyon meteorological conditions. Pfeffer et al. (1995) presented measurements of $\mathrm{NO}_{2}, \mathrm{CO}$, benzene, soot and other atmospheric pollutants carried out in two busy street canyons in Dusseldorf and Essen (Germany), as a part of a pilot study preparing the implementation of new regulations included in the German Federal Clean Air Act. The correlation between different pollutants and the influence of the wind conditions on measured concentrations were investigated. Namdeo et al. (1999) presented results from a monitoring study on traffic-related particulate pollution in urban areas. Field measurements of airborne fine and coarse particulate matter were taken in an urban street canyon in Nottingham (U.K.) and the correlation of the observed concentrations with traffic was studied. Venegas and Mazzeo (2000) reported $\mathrm{CO}$ concentrations measured in a deep street canyon in Buenos Aires (Argentina).

Vertical concentration gradients of CO were observed by Zoumakis (1995) in a busy street canyon in Athens (Greece). The monitoring results were used to derive an empirical expression relating pollutant concentration and height above the ground. Gaseous pollutants $\left(\mathrm{CO}, \mathrm{NO}_{\mathrm{x}}, \mathrm{O}_{3}\right)$ and aerosol particle concentrations were measured at two different heights within an urban street canyon in Lahti (Finland) by Väkevä et al. (1999). The main objective of this study was to investigate the factors leading to the formation of vertical concentration profiles within the canyon. TSP, $\mathrm{PM}_{10}$ and $\mathrm{PM}_{2.5}$ concentrations were measured in two open streets and two canyon sites in Hong Kong by Chan and Kwok (2000). These measurements showed that the dispersion of particulate matter was affected by the prevailing wind direction and the aspect ratio of the street. An exponential reduction of TSP and $\mathrm{PM}_{10}$ with height was observed.

Vachon et al. (2000) reported results (i.e. concentration, temperature and wind fields) from a full-scale experiment carried out in a street canyon (Rue de Strasbourg) in Nantes, France. This was the first campaign of the URBCAP project. which has the aim of assessing pollutant transformation processes within the urban canopy and validating smallscale dispersion models. Finally, with in the framework of the LIFE RESOLUTION project (Wright, 2001), benzene and $\mathrm{NO}_{2}$ measurements were taken in four European cities (Dublin, Madrid, Paris and Rome) in order to assess pollution levels with reference to established air quality standards, optimise the design of monitoring networks, and provide experimental data to support the validation of urban dispersion models. The sampling, carried out with diffusive tubes, covered a wide range of urban and suburban locations, including a number of street canyons.

4.2. Reduced-scale experiments 
Leisen and Sobottka (1980) made a comparison between field observations from two street canyons in Cologne (Germany) and wind tunnel measurements in order to investigate pollutant dispersion within urban streets and develop simulation models. Meroney et al. (1996) presented a wind tunnel study of car exhaust dispersion from street canyons in an urban environment. The main objective of this study was to investigate how pollution dispersion is affected by street geometry and particular emphasis was put on the design of a line source to realistically represent traffic emissions. The experiments were performed in the atmospheric boundary layer wind tunnel (BLASIUS) of the Meteorological Institute of Hamburg University (Germany). In a later study, Pavageau and Schatzmann (1999) investigated the concentration fluctuations in a reduced-scale urban canyon simulated within BLASIUS. Experimental data sets of wind tunnel measurements carried out in this facility for the validation of microscale dispersion models are available on the Internet (http://www.mi.uni-hamburg.de).

The differences between reduced- and full-scale experiments were illustrated by Liedtke et al. (1999), who compared field measurements obtained in a street canyon in Hanover (Germany) with wind tunnel results. The effect of using a simplified model of a street canyon in the wind tunnel was studied by taking measurements using different scaled models that included various levels of detail of the real canyon geometry. Significant differences were found in the results. In a later study, Schatzmann et al. (2000) showed how wind tunnel data can be used to supplement and enhance the value of field measurements for model validation purposes.

Rafailidis (1999) investigated the influence of atmospheric thermal stratification on urban street canyon ventilation in the EnFlo wind tunnel of the University of Surrey (U.K.). The measurements indicated that stable stratification conditions result in trapping the pollutants within the canyon. In a number of other wind tunnel studies (Rafailidis, 1997; 2000), the influence of building area density and roof shape on the wind field above and inside the urban canopy were highlighted. Uehara et al. (2000) also investigated the effects of thermal stratification on the wind flow in and above urban street canyons using the atmospheric diffusion wind tunnel at the Japanese National Institute for Environmental Studies (Ogawa et al.. 1981). The results showed that the wind vortex within the canyon becomes weaker when the atmosphere is stable. Kastner-Klein and Plate (1999) presented results from tracer dispersion experiments performed in a neutrally stratified atmospheric boundary layer wind tunnel in the Institute of Hydrology and Water Resources of the University of Karlsruhe (Germany). The influence of systematic parameter variation (i.e. building configuration, roof shape, wind direction ) on the concentration field within a street canyon was studied.

Gerdes and Olivari (1999) studied the wind and concentration fields generated within even and asymmetric street canyons under perpendicular winds using the L-2B wind tunnel of the von Karman Institute (Belgium). A strong influence of the surrounding landscape on pollutant dispersion was observed. The ratio of the height of the walls flanking the street was found to have a significant effect on the concentration patterns, while the width of the canyon was proved to be of less importance.

\subsection{Parametric modelling using field andlor wind tunnel measurements}

Johnson et al. (1973) developed STREET-SRI using data from the San Jose Street Canyon Experiment in California. Sobottka and Leisen $(1980 \mathrm{a}, \mathrm{b})$ created a modified version, called MAPS, which is quite similar in form and performance with the original model. Nicholson (1975) developed a simple box model that yields street-level average $C O$ concentrations in urban canyons under perpendicular and parallel wind conditions. Model results were proved to be in reasonable agreement with field data obtained in Frankfurt (Germany), Madison and Chicago (U.S.A.). Yamartino and Wiegand (1986) developed the CPBM using data from an extensive field monitoring programme in Bonner Strasse (Cologne). Part of the experimental data $\left(\mathrm{CO}\right.$ and $\left.\mathrm{NO}_{\mathrm{x}}\right)$ was used to evaluate the model. In the same study, the performance of CPBM (only for CO predictions) was compared with the performance of STREET-SRI and its modified version MAPS.

Hoydysh and Dabberdt (1988; 1994), and Dabberdt and Hoydysh (1991) carried out flow visualisation and tracer concentration measurements in the atmospheric boundary layer wind tunnel (ABLWT) of the Environmental Science and Services Corporation (U.S.A.). Pollutant dispersion was simulated using reduced-scale models for street canyons (both even and asymmetric) and intersections. Wind tunnel results were compared with concentrations calculated using STREET-SRI and the analytical model developed by Hotchkiss and Harlowe (1973). Finally, a simple exponential law describing vertical concentration profiles was established.

Hertel and Berkowicz (1989a) developed OSPM using measurements obtained in Jagtvej street in Copenhagen (Denmark). An intensive monitoring site was established in connection with a permanent air quality station operating in this street. A selection of the obtained wind and turbulence data was analysed by Nielsen (2000). OSPM has been applied 
to several street canyons in Copenhagen, Utrecht, Oslo, Helsinki, Beijing and other major cities (Berkowicz et al., 1996; Hertel and Berkowicz, 1989b; 1989c; Kukkonen et al., 2001; Fu et al., 2000). Based on the same principles, Buckland (1998) formulated AEOLIUS, which has been mainly used in the UK (Manning et al., 2000). Other authors (Sacré et al., 1995; Vardoulakis et al., 2002b) have presented slightly modified versions of OSPM.

Kono and Ito (1990a) presented the OMG VOLUME-SOURCE model, a microscale dispersion model that estimates concentrations of traffic-related pollutants in an urban area within $200 \mathrm{~m}$ from the roadside. The model parameters were determined using experimental data from five locations in Osaka ( $\mathrm{SF}_{6}$ was released as a tracer gas). Model results were compared by the same authors (Kono and Ito, 1990b) with concentrations calculated using three line source dispersion models. namely the JEA model (Japan Environmental Agency, 1982), the TOKYO model (Tokyo Metropolitan Government. 1983), and the HIWAY-2 model (Peterson, 1980).

Qin and Kot (1993) took measurements of $\mathrm{CO}$ and $\mathrm{NO}_{\mathrm{x}}$ at different heights and distances from the kerb within three asymmetric street canyons in Guangzhou City (China). STREET-SRI and a Gaussian plume model were used in this study to obtain $\mathrm{CO}$ and $\mathrm{NO}_{x}$ estimates, which were found to be in reasonable agreement with the observed values. Lanzani and Tamponi (1995) presented the microscale Lagrangian particle model GEM for the atmospheric dispersion of primary pollutants in the urban canopy. In the same study, GEM was validated against field measurements and compared with CPBM and STREET-SRI. The STREET-SRI model was also used in two independent studies in Argentina to calculate $\mathrm{CO}$ concentrations in street canyons in Cordoba (Stein and Toselli, 1996) and Buenos Aires (Bogo et al., 2001). A reasonably good agreement was found between measurements and predictions.

Hargreaves and Baker (1997) developed a Gaussian puff model, called PUFFER, to simulate the dispersion of vehicular pollutants in urban street canyons. This model, which explicitly takes into account vehicle induced turbulence, enables the user to investigate realistic transient situations such as traffic congestion and non-steady above canyon wind fields. A short sensitivity analysis and a comparison with STREET-SRI were also included in the same study. Gualtieri and Tartaglia (1998) developed a comprehensive air quality model, including traffic, emission and dispersion sub-models, for assessing pollutant concentrations in urban areas. A semi-empirical street canyon algorithm based on STREET-SRI and field measurements from Firenze (Tartaglia et al., 1995; Gualtieri and Tartaglia, 1997) was included in this model, which was finally integrated in a Geographic Information System (GIS).

Hassan and Crowther (1998a) developed a single box model for calculating first estimates of pollutant concentrations within urban canyons. The model parameters were derived using field CO measurements taken in Hope Street, Glasgow (U.K.). Furthemore, Hassan and Crowther (1998b) used PHOENICS to simulate wind flow and pollutant dispersion within the same canyon. The accuracy of the two-dimensional steady state numerical simulations was examined by comparing the predicted results with the field measurements.

Micallef and Colls (1999) developed a semi-empirical emission-dispersion model for predicting the temporal and spatial distribution of airborne particulate matter in street canyons. This model called SLAQ includes emission modules, meteorological pre-processors, modules for within-canyon processes, dispersion modules, and modules accounting for external influences. The dispersion module is mainly based on CPBM. Model features include a correction for the heat island effect. dry and wet deposition, particle settling, etc. SLAQ was evaluated against measurements obtained in a street in Loughborough (U.K.) using the automated near real time Kinetic Sequential Sampling (KSS) system (Colls and Micallef. 1099).

Coppalle et al. $(1999,2001)$ measured $\mathrm{NO}_{\mathrm{x}}$ and $\mathrm{CO}$ concentrations at different background and kerbside locations, including a street canyon (Rue Crevier), in a medium size French city (Rouen) during four weeks in winter. Using the obtained experimental data for parameterisation, Coppalle (1999) developed a simple mathematical model that calculates the vertical pollutant distribution inside a street canyon under low wind conditions. Vardoulakis et al. (2000, 2002a) carried out field experiments in two even (Bd. Voltaire and Rue de Rennes) and one asymmetric (Av. Leclerc) street canyons in Paris, France. Three semi-empirical dispersion models (STREEET-SRI, OSPM and AEOLIUS) were tested using the observed $\mathrm{CO}$ and benzene values (Fig. 4). Furthermore, an empirical relationship for calculating vertical concentration profiles within the streets was derived.

In the framework of AUTO-OIL II programme (Skouloudis, 2000), a large number of air quality modelling simulations were carried out in order to assess the compliance with the new EU air quality standards for $\mathrm{NO}_{2}, \mathrm{O}_{3}, \mathrm{CO}$, benzene, and $\mathrm{PM}_{10}$. An advanced methodology was established, incorporating models of different spatial scales, to provide air quality simulations down to street level. Two urban canyon models, namely OSPM and MICRO-CALGRID, were evaluated using measurements from Viale Murrilo (Milan) and Schildhorn Strasse (Berlin). 
Mensink and Lewyckyj (2001) developed the simple mathematical model STREET BOX, which assumes a uniform concentration distribution within a street canyon and is based on the concept of a turbulent intermittent shear flow shed from the roof of the upwind building. Model results were compared with benzene concentrations measured in ten streets in Antwerp (Belgium). Furthermore, benzene, $\mathrm{CO}$ and $\mathrm{NO}_{\mathrm{x}}$ concentrations calculated with STREET BOX were compared with values predicted using OSPM for a street canyon in Hanover. A discrepancy of $30 \%$ was found between the predictions from the two models.

Mukherjee and Viswanathan (2001) used the street canyon and Gaussian line source modules of the regional-scale dispersion model INDIC AIRVIRO to simulate ambient CO concentrations on two major roads in Singapore. The street canyon module based on STREET-SRI gave predictions comparable to the measured values at both the sites, despite the significant differences in street geometry.

Finally, Addison et al. (2000) presented an integrated method for predicting the spatial pollutant distribution within a street canyon. This method was based on a Lagrangian stochastic particle model superimposed on a known velocity and turbulence field. A traffic simulation package (Paramics) was used to model the flow of vehicles in realistic traffic conditions. This model is expected to be calibrated in the future using roadside measurements.

\subsection{CFD modelling using field and/or wind tunnel measurements}

Okamoto et al. (1994. 1996) developed a two-dimensional numerical air quality model that can be applied to street canyon cross sections under perpendicular wind conditions. It contains a wind field and a diffusion sub-model; the latter based on a Monte Carlo particle scheme. The model was evaluated using databases from field measurements carried out in three typical roadways surrounded by tall buildings in Tokyo (Japan). Furthermore, the predictive performance of the model was compared with the performance of STREET-SRI and of the APPS three-dimensional numerical model.

Leitl and Meroney (1997) used FLUENT to simulate numerically wind tunnel experiments conducted by Rafailidis et al. (1995) in the BLASIUS facility of the University of Hamburg. Several simplified two- and three-dimensional simulations were carried out to study the effect of emission rate and source design on flow structures and pollutant dispersion within the canyon. The advantages of using numerical CFD codes for optimising wind tunnel experiments were highlighted. In a later study. Meroney et al. (1999) compared numerical simulations carried out with FLUENT against other wind tunnel data from BLASIUS corresponding to several building shapes including a street canyon. Johnson and Hunter (1998) carried out a preliminary comparison between wind tunnel data from BLASIUS and simulations of wind flow and pollutant dispersion within street canyons using SCAM. This is a numerical code that consists of the wind model CITY and the dispersion model SCALAR (Johnson and Hunter, 1995).

Yoshikawa and Kunimi (1998) reported the development of an air quality simulation system, which calculates traffic volumes, evaluates the effects of building structures on pollutant dispersion along roadways, and takes into account photochemical reactions. The dispersion model, which serves as the platform of the overall simulation system, is a standard CFD code slightly modified to take into account vehicle induced turbulence inside street canyons. The model was validated against field data from an earlier tracer gas $\left(\mathrm{SF}_{6}\right)$ diffusion experiment carried out in Tokyo.

Riain et al. (1998) measured CO concentrations at different heights within an asymmetric canyon in central London, U.K. The FloVENT code was used in that case to simulate the concentration and wind fields created in the street. Soulhac et al. (1999) studied pollutant dispersion within street canyons (both even and asymmetric) and intersections using wind tunnel and numerical simulations carried out with MERCURE and CHENSI. The results were compared with two simple models: CARMEN for flow in a single street canyon and SIRANE for flow in a street network (Soulhac and Perkins, 1998).

Both CFD simulations using STAR-CD and wind tunnel measurements in EnFlo were carried out on a model arrangement of two intersecting street canyons, allowing the accuracy of predictions to be assessed (Scaperdas, 2000). It was found that even small changes in building alignment had a significant effect in the dispersion of pollutant in the street. Monitoring data from a permanent air quality station in central London were also used in this study (Scaperdas and Colvile, 1999).

Ketzel et al. (2000) carried out mathematical simulations of pollutant dispersion within street canyons using the relatively simple OSPM and the more complex MISKAM code. The results were compared with wind tunnel simulations and field measurements from two permanent monitoring stations in Copenhagen and Hanover. 
Huang et al. (2000) developed a two-dimensional numerical code, which was evaluated using data sets from tracer gas dispersion experiments carried out in an asymmetric street canyon in Tokyo. Chan et al. (2002) used FLUENT to simulate the wind flow and pollutant dispersion within an isolated street canyon. The validation of the numerical model was carried out using an extensive experimental database obtained from BLASIUS. Different turbulent models and street canyon configurations were studied. It was found that wider streets and lower buildings are favourable to pollutant dilution within canyons.

Garcia Sagrado et al. (2002) studied the two-dimensional wind flow and pollutant dispersion within urban canyons by means of wind tunnel measurements (L-2B wind tunnel, von Karman Institute) and numerical simulations carried out with FLUENT. it was observed that pollutant concentrations decreased with increasing the height of the downwind canyon wall. The influence of a third building situated upwind was also investigated.

\subsection{Theoretical CFD modelling}

Hunter et al. (1992) carried out a numerical investigation of typical three-dimensional flows within urban canyons in order to identify the key parameters that determine the transition between the different flow regimes for synoptic winds perpendicular to the street axis (see paragraph 2.2). Lee and Park (1994) developed a parameterisation scheme whereby the pollutant concentrations in an urban street canyon can be estimated from the source term, the meteorological conditions, and the street geometry using a two-dimensional time-dependant flow model. Sini et al. (1996) used CHENSI to study the influence of the geometrical aspect ratio of a street, which led to a refinement of Oke's (1988) classification into three flow regimes. In addition, it was shown that the differential heating of street surfaces (e.g. building facades) can influence the dispersion conditions within the canyon. Assimakopoulos et al. (1999) used MIMO to assess the influence of the numerical treatment of the wall boundary on the wind field and concentration patterns within two different two-dimensional street canyons.

Jicha et al. (2000) adopted a three-dimensional Eulerian-Lagrangian approach to study pollutant dispersion in an idealised street canyon taking traffic-induced turbulence into account. The Eulerian approach was based on the CFD code STAR-CD into which a Lagrangian model was integrated. Craig et al. (2001) also used STAR-CD coupled with a mathematical optimisation algorithm to identify the configuration of an idealised urban geometry that minimises pollution peaks. This methodology may be used to optimise traffic patterns or to modify street geometry for air pollution control. Xia and Leung (200la,b) used a Lagrangian particle together with a two-dimensional wind field model to simulate thow patterns for different building configurations within the urban canopy. The flow was visualised numerically by discharging a large number of particles into the computational domain. It was found that the higher concentrations did not always appear on the leeward side of the canyon and that the flow pattern was highly dependent on the configuration of the buildings and surrounding urban canopy.

Theodoridis and Moussiopoulos (2000) investigated the influence of building density and roof shape on the wind and dispersion characteristics in an urban area using CFX-TASCflow. In a later study, Theodoridis et al. (2001) applied the same model for simulating wind fields and pollutant dispersion in a complex urban area. In that case, two advanced turbulence models (namely the $k-\varepsilon$ and the RSM) were adopted and two grid refinement levels were tested. Venetsanos et al. (2001) carried out flow and dispersion calculations using ADREA-HF, a CFD code for simulating vapour cloud dispersion in complex terrain (Bartzis, 1991), to study the effects of moving vehicles on air pollution patterns within street canyons. The calculations were performed in a moving co-ordinate system with the car and site geometry fully resolved.

Chan et al. (2001) carried out a number of three-dimensional numerical simulations using CFX-5 in order to study flow regimes and corresponding pollutant dispersion characteristics for various types (i.e. aspect ratios) of urban street canyons. Some guidelines related to the geometry of the canyon were established for efficient pollutant dispersion. Finally, Jeong and Andrews (2002) used two numerical codes (TEACH-2E and HEATX) to study the two-dimensional flow structure of skimming flow fields in a street canyon at high Reynolds number. The critical aspect ratios of the transition between different vortex regimes were identified.

\section{Conclusions}

Considerable effort has been made in recent years to improve the scientific understanding of dispersion and transformation phenomena governing urban air quality. A large number of research studies have focused on street 
canyons, where the highest levels of air pollution often occur and the larger targets of impact are concentrated. The natural ventilation of urban streets is reduced mainly due to the presence of buildings. Within the urban canopy, wind vortices. low-pressure areas and channelling effects may be created under certain meteorological conditions, giving rise in some cases to air pollution hotspots. For example, high concentration levels have been often observed on the leeward side of regular canyons under perpendicular wind conditions.

Most authors have adopted different combinations of monitoring and modelling techniques for assessing air quality in urban street. There are several methods for monitoring roadside particulate and gaseous pollutants, each one of them having a number of advantages and drawbacks. Passive sampling can be used to obtain air quality data of high spatial resolution (both vertically and horizontally). On the other hand, active sampling can provide high temporal resolution. Hence. a combination of passive and active methods may be ideally used to capture short-term air pollution episodes and hotspots within a canyon. Mathematical and physical models are needed to optimise air quality monitoring, provide estimates for regulatory purposes, study different street geometries, and finally test future emission and traffic scenarios. Depending on their mathematical/physical principles, they may be more or less suitable for a number of applications.

\subsection{Gaussian plume models}

They are popular because of their relative simplicity and the possibility of easily including special features like deposition. source buoyancy, etc. Although they are mainly designed to simulate point or line sources in open terrain, they may also include complex terrain, street canyon and intersection modules (e.g. CALINE4). They can produce time series of pollutant concentrations and are used in a wide range of engineering and scientific applications. The main disadvantages of this method are the restricted number of different canyon configurations allowed and the relatively large amount of input information required.

\subsection{Parumetric street canyon models}

Semi-empirical parametric models (e.g. STREET-SRI, OSPM, AEOLIUS, etc.) are the most commonly used tools in regulatory street canyon applications. They are specially designed to produce time series of pollutant concentrations within near-regular canyons, and they require a relatively small amount of input information, user expertise and computational resources. On the other hand, they are based on a number of empirical assumptions and parameters that might not be applicable to all urban environments. For this reason, they should be re-calibrated against a small (at least) number of field measurements, if they are to be applied to new locations.

\subsection{CFD models}

CFD is a powerful modelling technique that might be applied to many different fields of engineering and scientific research. As far as roadside air quality is concerned, the main advantage of the method is that it can reproduce the entire flow and concentration fields within urban canyons of any configuration, if the necessary input data are available. Furthermore, the details of urban canopy can be efficiently taken into account, thanks to the fine grid generation capabilities of modern CFD models.

Traditionally. CFD has been seen as a modelling technique requiring long computational times, expensive hardware/software resources, and high expertise. However, recent computer hardware developments have contributed to the spread of CFD modelling, since the speed and memory capacities of PCs are now sufficient for relatively small applications. Furthermore, CFD codes have become much easier to use due to improvements in interface facilities (although they still require a reasonable level of knowledge of flow physics). It should be kept in mind that the main objective of an environmental CFD exercise is to improve the understanding of the behaviour of a system, rather than obtaining results readily comparable with regulatory standards.

\subsection{Redrecet-scale models}

Physical modelling in wind tunnels has been proved very useful in investigating specific characteristics of pollutant dispersion within the urban canopy (e.g. effects of roof shape, moving and fixed obstacles, etc.). Although wind tunnel experiments have the advantage of providing controlled dispersion conditions (e.g. wind velocity, stability, etc.), they might be seen as relatively expensive and difficult to set up. Wind tunnel measurements are often used in the development and validation of operational mathematical models. 
For the selection of the appropriate dispersion model, one should be aware of the capabilities, underlying assumptions and limitations of the available software. Although they vary greatly in terms of sophistication, simple and complex models can be both useful in different air quality applications (Berkowicz, 1997). For regulatory purposes, it is recommended to use a simple screening model initially, before adopting a more sophisticated approach that will include simulations with a more complex code and a limited (at least) number of measurements. For quick air quality surveys and traffic planning, simulations with a simple model like CAR might suffice. On the other hand, air quality monitoring network design may require both parametric modelling for an initial selection of the streets to be implemented and then CFD simulations to identify representative locations within these streets. Finally, it should be remembered that the accuracy of model predictions is bounded by the accuracy of input data such as emission factors, traffic and meteorological data, street geometry, etc. Decision-makers should use modelling results cautiously, when relevant field measurements are not available.

Future research on urban air quality is expected to focus on topics related to low wind conditions, thermal effects due to solar radiation, microscale dispersion around fixed and moving obstacles, and pollutant dispersion in irregular canyons and other complex urban microenvironments (e.g. intersections, parking spaces, etc.). Despite the large number of existing codes, there is still a need for scientifically sound, user-friendly and well-documented air quality models, as well as for high quality experimental data sets.

\section{Acknowledgements}

We would like to thank Emmanuelle Cohen-Solal (RENAULT), Athena Scaperdas (WSAtkins), Shailendra Mudgal and Olivier Le Bihan (INERIS) for their comments on the manuscript. Our appreciation is also extended to Carine Lipari (AUXIRBAT) for co-ordinating this study. 


\section{References}

Addison P.S., Currie J.1., Low D.J., McCann J.M., 2000. An integrated approach to street canyon pollution modelling. Environmental Monitoring and Assessment 65, 333-342.

ADEME, 1998. Emissions de polluants et consommations liées à la circulacion routière. Paris, France.

Anderson K.R.. Avol E.L., Edwards S.A., Shamoo D.A., Peng R.C., Linn W.S., Hackney J.D., 1992. Controlled exposures of volunteers to respirable carbon and sulfuric acid aerosols. J. Air and Waste Management Association 42, $770-776$.

ApSimon H.M. Rejlova K., Mediavilla-Sahagun A., Gonzales T., Warren R.F., Colvile R., 2001. Modelling urban background concentrations. 3rd International Conference on Urban Air Quality, Loutraki, Greece.

Assimakopoulos V., Ehrhard J., Theodoridis G., Moussiopoulos N., ApSimon H., 1999. Assessing the influence of near wall treatment on the wind and dispersion characteristics in urban areas. 6th International Conference on Harmonisation within Atmospheric Dispersion Modelling for Regulatory Purposes, Rouen, France.

Baker C.J.. Hargreaves D.M., 2001. Wind tunnel evaluation of a vehicle pollution dispersion model. J. Wind Engineering and Industrial Aerodynamics 89, 187-200.

Bartzis J.G.. 1991. ADREA-HF: A three-dimensional finite volume code for vapour cloud dispersion in complex terrain. Report EUR 13580 EN.

Benson P.E.. 1984. CALINE4 - A dispersion model for predicting air pollutant concentrations near roadways. Office of Transportation Laboratory. California Department of Transportation. Sacramento, USA.

Benson P.E.. 1992. A review of the development and application of the CALINE3 and 4 models. Atmospheric Environment 26B (3). 379-390.

Berkovicz R.. 1997. Modelling street canyon pollution: model requirements and expectations. Int. J. Environment and Pollution 8 (3-6), 609-619.

Berkowicz R. 2000a. OSPM - A parameterised street pollution model. Environmental Monitoring and Assessment 65 , 323-331.

Berkowicz. R. 2000b. A simple model for urban background pollution. Environmental Monitoring and Assessment 65 , $259-267$

Berkowicz R.. Hertel O., Larsen S.E., Sorensen N.N., Nielsen M., 1997. Modelling traffic pollution in streets. NERI, Roskilde. Denmark.

Berkowicz R.. Palmgren F., Hertel O., Vignati E., 1996. Using measurements of air pollution in streets for evaluation of urban air quality - meteorological analysis and model calculations. The Science of the Total Environment 189/190, 259-265.

Bitan A.. 1992. The high climatic quality city of the future. Atmospheric Environment 26B, 313-329.

Bogo H.. Gomez D.R.. Reich S.L., Negri R.M., San Roman E., 2001. Traffic pollution in a downtown site of Buenos Aires City. Atmospheric Environment 35, 1717-1727.

Boubel R.W., Fox D.L., Turner D.B., Stern A.C., 1994. Fundamentals of air pollution. Academic Press.

Buckland A.T., 1998. Validation of a street canyon model in two cities. Environmental Monitoring and Assessment 52 , 255-267.

Buckland A.T.. Middleton D.R., 1999. Nomograms for calculating pollution within street canyons. Atmospheric Environment 33, 1017-1036.

Burnett R.T., Philips O., Ozkaynak H., 1998. The association between ambient carbon monoxide levels and mortality in Toronto, Canada. J. Air and Waste Management Association 48, 689-700.

Capannelli G., Gollo E., Munari S., Ratto G., 1977. Nitrogen oxides: Analysis of urban pollution in the city of Genoa. Atmospheric Environment 11, 719-727.

Carissimo B.. Dupont E., Musson-Genon L., Marchand O., 1995. Note de principe du code MERCURE version 3.1. EDF-DER. HE-3395007B.

Carruthers D.J.. Holroyd R.J., Hunt J.C.R., Weng W.S., Robins A.G., Apsley D.D., Thompson D.J., Smith F.B., 1994. UK-ADMS: A new approach to modelling dispersion in the earth's atmospheric boundary layer. J. Wind Engineering and Industrial Aerodynamics, 52, 139-153.

Chan A.T., So E.S.P.. Samad S.C., 2001. Strategic guidelines for street canyon geometry to achieve sustainable street air quality. Amospheric Environment 35, 4089-4098.

Chan L.Y.. Kwok W.S., 2000. Vertical dispersion of suspended particulates in urban area of Hong Kong. Atmospheric Environment 34, 4403-4412.

Chan T.L., Dong G., Leung C.W., Cheung C.S., Hung W.T., 2002. Validation of a two-dimensional pollutant dispersion model in an isolated street canyon. Atmospheric Environment 36, 861-872.

Chauvet C. Leitl B., Schatzmann M., 2001. High resolution flow measurements in an idealised urban street canyon. 3rd International Conference on Urban Air Quality, Loutraki, Greece.

Cicolella A.. 1997. Evaluation des risques pour la santé liés au benzène. INERIS, Verneuil, France. 
Cocheo V., Sacco P., Boaretto C., De Saeger E., Perez-Ballesta P., Skov H., Goelen E., Gonzalez N., Baeza-Caracena A., 2000. Urban benzene and population exposure. Nature 404, 141-142.

Colls J.J., Micallef A., 1997. Towards better human exposure estimates for setting of air quality standards. Atmospheric Environment $31(24), 4253-4254$.

Colls J.J., Micallef A., 1999. Measured and modelled concentrations and vertical profiles of airborne particulate matter within the boundary layer of a street canyon. The Science of the Total Environment 235, 22 1-233.

Colvile R.N., Hutchinson E.J., Mindell J.S., Warren R.F., 2001. The transport sector as a source of air pollution. Atmospheric Environment 35, 1537-1565.

Cooper C.D.. 1987. Indirect source impact analysis - carbon monoxide modeling. J. Air Pollution Control Association $37,1308-1313$.

Coppalle A.. 1999. A street canyon model for low wind speed conditions. 6th International Conference on Harmonisation within Atmospheric Dispersion Modelling for Regulatory Purposes, Rouan, France.

Coppalle A., Delmas V., Hamida M., 1999. Variability of $\mathrm{NO}_{\mathrm{x}}$ and $\mathrm{CO}$ outside concentrations measured at pedestrian level and at different locations in an urban area. 2nd International Conference on Urban Air Quality, Madrid, Spain.

Coppalle A.. Delmas V., Bobbia M., 2001. Variability of $\mathrm{NO}_{x}$ and $\mathrm{NO}_{2}$ concentrations observed at pedestrian level in the city centre of a mediuin sized urban area. Atmospheric Environment 35, $5361-5369$.

Craig K.J., de Kock D.J., Snyman J.A., 2001. Minimizing the effect of automotive pollution in urban geometry using mathematical optimization. Atmospheric Environment 35, 579-587.

Croxford B.. Penn A., 1998. Siting considerations for urban pollution monitors. Atmospheric Environment 32 (6), $1049-$ 1057.

Dab W.. Ségala C.. Dor F., Festy B., Lameloise P., Le Moullec Y., Le Tertre A., Médina S., Quénel P., Wallaert B., Zmirou D. 2001. Pollution atmosphérique et santé: Corrélation ou causalité? Le cas de la relation entre l'exposition aux particules et la mortalité cardio-pulmonaire. J. Air and Waste Management Association 51, 203-219.

Dabberdt W.F.. Hoydysh W.G., 1991. Street canyon dispersion: sensitivity to block shape and entrainment. Atmospheric Environment 25A (7), 1143-1153.

Dabberdt W.F.. Ludwig F.L., Johnson W.B., 1973. Validation and applications of an urban diffusion model for vehicular pollutants. Atmospheric Environment 7, 603-618.

den Boeft J.. Eerens H.C.. den Tonkelaar W.A.M., Zandeveld P.Y.J., 1996. CAR International: a simple model to determine city street air quality. The Science of the Total Environment 189/190, 321-326.

DePaul F.T.. Sheih C.M., 1985. A tracer study of dispersion in an urban street canyon. Atmospheric Environment 19 (4), $555-559$.

DePaul F.T.. Sheih C.M.. 1986. Measurements of wind velocities in a street canyon. Atmospheric Environment 20 (3), $455-459$.

Derwent R.G.. Middleton D.R., 1996. An empirical function for the ratio $\mathrm{NO}_{2}$ : $\mathrm{NO}_{\mathrm{x}}$. Clean Air 26 (3). National Society for Clean Air and Environmental Protection, Brighton, U.K

Dockery D.W.. Pope C.A., 1994. Acute respiratory effects of particulate air pollution. Annual Reviews of Public Health $15,107-132$.

Eerens H.C.. Sliggers C.J., van den Hout S.D., 1993. The CAR model: The Dutch method to determine city street air quality. Atmospheric Environment 27B, 389-399

Eggleston S., Gaudioso D., Gorissen N., Joumard R., Rijkeboer R.C., Samaras Z., Zierock K.-H., 1993. CORINAIR working group on emission factors for calculating 1990 emissions from road traffic. Volume 1: Methodology and emission factors. Luxembourg, Commission of the European Communities.

Ehrhard J.. Khatib I.A., Winkler C., Kunz R., Moussiopoulos N., Ernst G., 2000. The microscale model MiMO: development and assessment. J. Wind Engineering and Industrial Aerodynamics 85, 163-176.

Eichhorn J., 1995. Validation of a microscale pollution dispersal model. 21st International Meeting on Air Pollution Modeling and its Application, Baltimore, Maryland, USA.

EPA, 1996. National ambient air quality standards for ozone and particulate matter. U.S. Fed. Regist. 61 (114), 2971929725.

Eskridge R.E., Rao S.T., 1986. Turbulent diffusion behind vehicles: Experimentally determined turbulence mixing parameters. Atmospheric Environment 20, 851-860.

European Commission, 1999. Council Directive 1999/30/EC relating to limit values for sulphur dioxide, nitrogen dioxide and nitrogen oxides, particles and lead in ambient air. Official Journal of the European Communities, Brussels, 29.06.1999

European Commission, 2000. Council Directive 2000/69/EC relating to limit values for benzene and carbon monoxide in ambient air. Official Journal of the European Communities, Brussels, 13.12.2000.

Fenger J., 1999. Urban air quality. Atmospheric Environment 33, 4877-4900.

Fu L., Hao J., Hertel O., Berkowicz R., 2000. Modeling traffic-related air pollution in street canyons of Beijing. J. Air and Waste Management Association 50, 2060-2066. 
Garcia Sagrado A.P., van Beeck J., Rambaud P., Olivari D., 2002. Numerical and experimental modelling of pollutant dispersion in a street canyon. J. Wind Engineering and Industrial Aerodynamics (in press).

Gayev Y.A.. Savory E., 1999. Influence of street obstructions on flow processes within urban canyons. J. Wind Engineering and Industrial Aerodynamics 82, 89-103.

Georgii H-W., 1969. The effects of air pollution on urban climates. Bulletin of the World Health Organization 40, 624635.

Gerdes F.. Olivari D., 1999. Analysis of pollutant dispersion in an urban street canyon. J. Wind Engineering and Industrial Aerodynamics 82, 105-124.

Gordon G.E., Pierson W.R., Daisey J.M., Lioy P.J., Cooper J.A., Watson J.G., Cass G.R., 1984. Considerations for design of source apportionment studies. Atmospheric Environment 18, 1567-1582.

Gosman A.D., 1999. Developments in CFD for industrial and environmental applications in wind engineering. J. Wind Engineering and Industrial Aerodynamics 81, 21-39.

Gualtieri G., Tartaglia M., 1997. A street canyon model for estimating $\mathrm{NO}_{x}$ concentrations due to road traffic. Measurements and Modelling in Environmental Pollution, Editor C.A. Brebbia, Computational Mechanics Publications, Southampton, U.K.

Gualtieri G.. Tartaglia M., 1998. Predicting urban traffic air pollution: A GIS framework. Transportation Research - D 3 (5), 329-336.

Hargreaves D.M., Baker C.J., 1997. Gaussian puff model of an urban street canyon. J. Wind Engineering and Industrial Aerodynamics 69-71, 927-939.

Härkönen J.. Valkonen E., Kukkonen J., Rantakrans E., Jalkanen L.. Lahtinen K., 1995. An operational dispersion model for predicting pollution from a road. Int. J. Environment and Pollution 5 (4-6), 602-610.

Harrison R.M.. Yin J., 2000. Particulate matter in the atmosphere: which particle properties are important for its effects on health? The Science of the Total Environment 249, 85-101.

Hassan A.A., Crowther J.M., 1998a. A simple model of pollutant concentrations in a street canyon. Environmental Monitoring and Assessment 52, 269-280.

Hassan A.A.. Crowther J.M., 1998b. Modelling of fluid flow and pollutant dispersion in a street canyon. Environmental Monitoring and Assessment 52, $281-297$.

Hertel O. Berkowicz R., 1989a. Modelling pollution from traffic in a street canyon. Evaluation of data and model development. NERI, Roskilde, Denmark.

Hertel O.. Berkowicz R.. 1989b. Modelling $\mathrm{NO}_{2}$ concentrations in a street canyon. NERI, Roskilde, Denmark.

Hertel O.. Berkowicz R., 1989c. Operational Street Pollution Model (OSPM): Evaluation of the model on data from from St. Olavs Street in Oslo. NERI, Roskilde. Denmark.

Hoek G.. Brunekreef B., Verhoeff A, van Wijnen J., Fischer P., 2000. Daily mortality and air pollution in the Netherlands. J. Air and Waste Management Association 50, 1380-1389.

Hotchkiss R.S., Harlow F.H., 1973. Air pollution transport in street canyons. EPA-R4-73-029.

Hoydysh W.G.. Dabberdt W.F., 1988. Kinematics and dispersion characteristics of flows in asymmetric street canyons. Atmospheric Environment 22 (12), 2677-2689.

Hoydysh W.G., Dabberdt W.F., 1994. Concentration fields at urban intersections: Fluid modelling studies. Atmospheric Environment 28(11), 1849-1860.

Huang C.H., 1979. A theory of dispersion in turbulent shear flow. Atmospheric Environment 13, 453-463.

Huang H., Akutsu Y., Arai M., Tamura M., 2000. A two-dimensional air quality model in an urban street canyon: evaluation and sensitivity analysis. Atmospheric Environment 34, 689-698.

Hunter L.J., Johnson G.T.. Watson I.D., 1992. An investigation of three-dimensional characteristics of flow regimes within the urban canyon. Atmospheric Environment 26B (4), 425-432.

Japan Environmental Agency, 1982. Manual for the nitrogen oxides total pollution load control (in Japanese).

Jeong S.J., Andrews M.J., 2002. Application of the k-e turbulence model to the high Reynolds number skimming flow field of an urban street canyon. Atmospheric Environment 36, 1137-1145.

Jicha M.. Pospisil J., Katolicky J., 2000. Dispersion of pollutants in street canyon under traffic induced flow and turbulence. Environmental Monitoring and Assessment 65, 343-351.

Johnson G.T.. Hunter L.J., 1995. A numerical study of dispersion of passive scalars in city canyons. Boundary-Layer Meteorology 75, 235-262:

Johnson G.T., Hunter L.J., 1998. Urban wind flows: wind tunnel and numerical simulations - a preliminary comparison. Environmental Modelling and Software 13, 279-286.

Johnson G.T.. Hunter L.J.. 1999. Some insights into typical urban canyon airflows. Atmospheric Environment 33, 39913999

Johnson W.B., Ludwig F.L., Dabberdt W.F., Allen R.J., 1973. An urban diffusion simulation model for carbon monoxide. J. Air Pollution Control Association 23, 490-498. 
Jones S.G.. Fisher B.E.A., Gonzalez-Flesca N., Sokhi R., 2000. The use of measurement programmes and models to assess concentrations next to major roads in urban areas. Environmental Monitoring and Assessment 64, $531-547$.

Karim Md. M., Ohno T., 2000. Air quality planning and empirical model to evaluate SPM concentrations. J. Environmental Engineering, December 2000, 1116-1124.

Kastner-Klein P., Berkowicz R., Plate E.J., 2000. Modelling of vehicle-induced turbulence in air pollution studies for streets. Int. J. Environment and Pollution 14 (1-6), 496-507.

Kastner-Klein P., Fedorovich E., Rotach M.W., 2001. A wind tunnel study of organised and turbulent air motions in urban street canyons. J. Wind Engineering and Industrial Aerodynamics 89, 849-861.

Kastner-Klein P., Plate E.J., 1999. Wind-tunnel study of concentration fields in street canyons. Atmospheric Environment 33, 3973-3979.

Kastner-Klein P.. Rotach M.W., 2001. Parameterization of wind and turbulent shear stress profiles in the urban roughness sublayer. 3rd International Conference on Urban Air Quality, Loutraki, Greece.

Ketzel M. Berkowicz R., Lohmeyer A., 2000. Comparison of numerical street dispersion models with results from wind tunnel and field measurements. Environmental Monitoring and Assessment 65, 363-370.

Ketzel M., Louka P.. Sahm P., Guilloteau E., Sini J.-F., Moussiopoulos N., 2001. Intercomparison of numerical urban dispersion models - Part II: Street canyon in Hannover, Germany. 3rd International Conference on Urban Air Quality, Loutraki. Greece.

Kim J-J., Baik J-J., 2001. Urban street-canyon flows with bottom heating. Atmospheric Environment 35, $3395-3404$.

Kingham S.. Briggs D., Elliott P., Fischer P., Lebret E., 2000. Spatial variations in the concentrations of traffic related pollutants in indoor and outdoor air in Huddersfield, England. Atmospheric Environment 34, 905-916.

Kono H. Ito S. 1990a. A micro-scale dispersion model for motor vehicle exhaust gas in urban areas - OMG VOLUMESOURCE model. Atmospheric Environment 24B (2), 243-251.

Kono H. Ito S., 1990b. A comparison of concentration estimates by the OMG volume-source dispersion model with three line source dispersion models. Atmospheric Environment 24B (2), 253-260.

Kovar-Panskus A., Louka P., Mestayer P.G., Savory E., Sini J.-F., Toy N., 2001 b. Influence of geometry on the flow and turbulence characteristics within urban street canyons - intercomparison of the wind tunnel experiments and numerical solutions. 3rd International Conference on Urban Air Quality, Loutraki, Greece.

Kovar-Panskus A.. Moulinneuf L., Robins A., Savory E., Toy N., 200la. The influence of solar-induced wall heating on the flow regime within urban street canyons. 3rd International Conference on Urban Air Quality, Loutraki, Greece.

Kühlwein J.. Friedrich R., 2000. Uncertainties of modelling emissions from road transport. Atmospheric Environment $34,4603-4610$.

Kukkonen J.. Valkonen E., Walden J., Koskentalo T., Aarnio P., Karppinen A., Berkowicz R., Kartastenpää R., 2001. A measurement campaign in a street canyon in Helsinki and comparison of results with predictions of the OSPM model. Atmospheric Environment 35, 231-243.

Lanzani G.. Tamponi M., 1995. A microscale Lagrangian particle model for the dispersion of primary pollutants in a street canyon. Sensitivity analysis and first validation trials. Atmospheric Environment 29 (23), 3465-3475.

Larssen S.. Tonnesen, Clench-Aas J., Aarnes M.J., Arnesen K., 1993. A model for car exhaust exposure calculations to investigate health effects of air pollution. The Science of the Total Environment 134, 51-60.

Le Bihan O.. Wăhlin P., Ketzel M., Palmgren F., Berkowicz R., 2001. Application of dispersion modelling for analysis of particle pollution sources in a street canyon. 3rd International Conference on Urban Air Quality, Loutraki, Greece.

Lee I.Y.. Park H.M., 1994. Parameterization of the pollutant transport and dispersion in urban street canyons. Atmospheric Environment 28, 2343-2349.

Leisen P.. Sobottka H., 1980. Simulation of the dispersion of vehicle exhaust gases in street canyons: Comparison of wind tunnel investigations and full-scale measurements. IMA Conference on Modeling of Dispersion in Transport Pollution, Southend-on-Sea, England, 129-146.

Leitl B.M., Chauvet C., Schatzmann M., 2001. Effects of geometrical simplification and idealization on the accuracy of microscale dispersion modelling. 3rd International Conference on Urban Air Quality, Loutraki, Greece.

Leitl B.M. Meroney R.N., 1997. Car exhaust dispersion in a street canyon. Numerical critique of a wind tunnel experiment. J. Wind Engineering and Industrial Aerodynamics 67/68, 293-304.

Levi Alvares S., Sini J.-F., 1992. Simulation of diffusion within an urban street canyon, J. Wind Engineering 52, $114-$ 119.

Liedtke J.. Leitl B., Schatzmann M., 1999. Dispersion in a street canyon: comparison of wind tunnel experiments with field measurements. Proceedings of EUROTRAC Symp.'98, Editors P.M. Borrel and P. Borrel, WIT Press, Southampton, 800-810.

Louka P., Vachon G., Sini J.-F., Mestayer P.G., Rosant J.-M., 2001. Thermal effects on the airflow in a street canyon Nantes'99 experimental results and model simulations. 3rd International Conference on Urban Air Quality, Loutraki, Greece. 
Manning A.J., Nicholson K.J., Middleton D.R., Rafferty S.C., 2000. Field study of wind and traffic to test a street canyon pollution model. Environmental Monitoring and Assessment 60, 283-313.

McRae G.J.. Seinfeld J.H., 1983. Development of a second-generation mathematical model for urban air pollution - II. Evaluation of model performance. Atmospheric Environment 17, 501-522.

Mensink C., Lewyckyj N., 2001. A simple model for the assessment of air quality in streets. Int. J. Vehicle Design 27 (14), 242-250

Meroney R.N., Leitl B.M., Rafailidis S., Schatzmann M., 1999. Wind-tunnel and numerical modeling of flow and dispersion about several building shapes. J. Wind Engineering and Industrial Aerodynamics 81, 333-345.

Meroney R.N., Pavageau M., Rafailidis S., Schatzmann M., 1996. Study of line source characteristics for 2-D physical modelling of pollutant dispersion in street canyons. J. Wind Engineering and Industrial Aerodynamics 62, 37-56.

Micallef A.. Colls J.J., 1999. Measuring and modelling the airborne particulate matter mass concentration field in the street environment: model overview and evaluation. The Science of the Total Environment 235, 199-210.

Mukherjee P.. Viswanathan S., 2001. Carbon monoxide modeling from transportation sources. Chemosphere 45, 10711083.

Nakamura Y., Oke T.R., 1988. Wind, temperature and stability conditions in an east-west oriented urban canyon. Atmospheric Environment 22 (12), 2691-2700.

Namdeo A.K.. Colls J.J., Baker C.J., 1999. Dispersion and re-suspension of fine and coarse particulates in an urban street canyon. The Science of the Total Environment 235, 3-13.

Nicholson S.E.. 1975. A pollution model for street-level air. Atmospheric Environment. 9, 19-31.

Nielsen M.. 2000. Turbulent ventilation of a street canyon. Environmental Monitoring and Assessment 65, 389-396.

Ntziachristos L.. Samaras Z., 1997. COPERT II: Computer programme to calculate emissions from road transport User's manual. European Topic Centre on Air Emissions, EEA.

Ntziachristos L.. Samaras Z., 2000. COPERT III: Computer programme to calculate emissions from road transport Methodology and emission factors. European Topic Centre on Air Emissions, EEA.

Nyberg F.. Gustavsson P., Järup L., Bellander T., Berglind N., Jakobsson R., Pershagen G.,et al., 2000. Urban air pollution and lung cancer in Stockholm. Epidemiology 11 (5), 487-495.

Ogawa Y.. Diosey P.G., Uehara K., Ueda H., 1981. A wind tunnel for studying the effects of thermal stratification in the atmosphere. Atmospheric Environment 15, 807-821.

Okamoto S.. Lin F.C.. Yamada H.. Shiozawa K., 1994. Development and application of an air quality simulation model for automobile emissions in a street canyon. Proceedings of the 7th IUAPPA Regional Conference on Air Pollution and Waste Issues. Taipei, Taiwan, 97-106.

Okamoto S.. Lin F.C.. Yamada H., Shiozawa K., 1996. Evaluation of a two-dimensional numerical model for air quality simulation in a street canyon. Atmospheric Environment 30, 3909-3915.

Oke T.R., 1988. Street design and urban canopy layer climate. Energy and Buildings 11, 103-113.

Ott W. Eliassen R., 1973. A survey technique for determining the representativeness of urban air monitoring stations with respect to carbon monoxide. J. Air Pollution Control Association 23, 685-690.

Owen B.. Edmunds H.A., Carruthers D.J., Raper D.W., 1999. Use of a new generation urban scale dispersion model to estimate the concentration of oxides of nitrogen and sulphur dioxide in a large urban area. The Science of the Total Environment 235, 277-291.

Pal Arya S. 1988. Introduction to Micrometeorology, Academic Press Inc.

Palmgren F.. Kemp K.. 1999. The Danish Air Quality Monitoring Programme. Annual Report No. 296, NERI, Roskilde, Denmark.

Patankar S.V., Spalding D.B., 1972. A calculation procedure for heat, mass and momentum transfer in three-dimensional parabolic flows, Int. J. Heat Mass Transfer 15, 1787.

Pavageau M., Rafailidis S., Schatzmann M., 1996. A comprehensive experimental databank for the verification of urban car emission dispersion models. 4th Workshop on Harmonisation within Atmospheric Dispersion Modelling for Regulatory Purposes, Ostende, Vol. 2, 443-450.

Pavageau M., Schatzmann M.. 1999. Wind tunnel measurements of concentration fluctuations in an urban street canyon. Atmospheric Environment 33, 3961-3971.

Peterson W.B., 1980. User's guide for HIGHWAY-2: a highway air pollution model. EPA-600/8-80-018.

Petit C.. de Jerphanion M., Brou M., 2000. Analyse de sensibilité d'un logiciel d'évaluation des immissions liées au trafic automobile, au niveau de la rue. Le cas de STREET 3.1. 9th International Symposium "Transport and Air Pollution", Avignon, France.

Pfeffer H.U., Friesel J., Elbers G., Beier R., Ellermann K., 1995. Air pollution monitoring in street canyons in North Rhine-Westphalia, Germany. The Science of the Total Environment 169, 7-15.

Qin Y., Kot S.C.. 1993. Dispersion of vehicular emission in street canyons, Guangzhou city, South China (P.R.C.). Atmospheric Enviromment 27B, 283-291. 
Rafailidis S., 1997. Influence of building area density and roof shape on the wind characteristics above a town. Boundary-Layer Meteorology 85, 255-271.

Rafailidis S., 1999. Influence of stable atmospheric thermal stratification on urban street canyon reaeration. 6th International Conference on Harmonisation within Atmospheric Dispersion Modelling for Regulatory Purposes, Rouan, France.

Rafailidis S., 2000. Near-field geometry effects on urban street canyon measurements for model validation. Int. J. Enviromment and Pollution 14 (1-6), 538-546.

Rafailidis S., Pavageau M., Schatzmann M., 1995. Wind tunnel simulation of car emission dispersion in urban street canyons, Amalen der Meteorologie, Deutsche Meteorologische Gesellschaft, Munich.

Riain C.M.N., Fisher B., Martin C.J., Littler J., 1998. Flow field and pollution dispersion in a central London street. Environmental Monitoring and Assessment 52, 299-314.

Sacré C.. Chiron M. Flori J-P., 1995. Elaboration d'un indice d'exposition à la pollution atmoshérique d'origine automobile à l'usage des études épidémiologiques. The Science of the Total Environment 169, 63-69.

Sahn P.. Louka P.. Ketzel M., Guilloteau E., Sini J.-F., 2001. Intercomparison of numerical urban dispersion models Part l: Street canyon and single building configurations. 3rd International Conference on Urban Air Quality, Loutraki, Greece.

Samaras Z.C.. Zachariadis T.I., 1994. In Proceedings of the Emission Inventory: Perception and Reality. Air and Waste Management Association. Pittsburgh, PA, pp. 12-27, VIP-38.

Scaperdas A.. 2000. Modelling air flow and pollutant dispersion at urban canyon intersections. PhD thesis, T.H. Huxley School of Environment, Earth Science and Engineering. London, Imperial College, University of London.

Scaperdas A.. Colvile R.N., 1999. Assessing the representativeness of monitoring data from an urban intersection site in central London. UK. Atmospheric Environment 33, 661-674.

Schatzmann M. Leitl B., Liedtke 1., 2000. Dispersion in urban environments: Comparison of field measurements with wind tumel results. Environmental Monitoring and Assessment 65, 249-257.

Schatzmann M.. Liedtke J.. Leitl B., Kovar A., 1999. Modelling and validation in an urban environment. Proceedings of EUROTRAC Symposium 1998, Editors P.M. Borrel and P. Borrel, WIT Press, 673-678.

Sharma P.. Khare M., 2001. Modelling of vehicular exhausts - a review. Transportation Research - D 6, 179-198.

Sini J.-F.. Anquetin S., Mestayer P.G., 1996. Pollutant dispersion and thermal effects in urban street canyons. Atmospheric Environment 30 (15), 2659-2677.

Skouloudis A.N.. 2000. The AUTO-OIL II programme: air quality report. Report of Working Group 1 on Environmental Objectives for the Directorate General of the Environment, European Communities.

Skov H.. Lindskog A., Palmgren F., Christensen C.S., 2001. An overview of commonly used methods for measuring benzene in ambient air. Atmospheric Environment 35, S141-S148.

Sobottka H. Leisen P., 1980a. Vehicle exhaust gas emissions in city streets and their distributions; comparison of measurements and model aspects. IMA Conference on Modeling of Dispersion in Transport Pollution, Southend-onSea, England.

Sobottka H.. Leisen P., 1980b. Pollutant dispersion of vehicle exhaust gases in street canyons. Proceedings of the Fifth International Clean Air Congress, Buenos Aires, Argentina.

Soulhac L., Mejean P., Perkins R.J., 1999. Modelling transport and dispersion of pollutants in street canyons. 6th International Conference on Harmonisation within Atmospheric Dispersion Modelling for Regulatory Purposes, Rouan, France.

Southac L., Perkins R.J., 1998. A new model for flow and dispersion in a street canyon. 23rd NATO/CCMS meeting, Varna. Bulgaria.

Spadaro J.V., Rabl A., 2001. Damage costs due to automotive air pollution and the influence of street canyons. Atmospheric Environment 35, 4763-4775.

Stedman J.R.. Goodwin J.W.L., King K., Murrells T.P., Bush T.J., 2001. An empirical model for predicting urban roadside nitrogen dioxide concentrations in the UK. Atmospheric Environment 35, 1451-1463.

Stein A.F.. Toselli B.M., 1996. Street level air pollution in Cordoba city, Argentina. Atmospheric Environment 30, 3491 3495.

Stern R., Yamartino R.J., 2001. Development and first evaluation of micro-calgrid: a 3-D, urban-canopy-Scale photochemical model. Atmospheric Environment 35, S149-S165.

Tartaglia M., Giannone A., Gualtieri G., Barbaro A., 1995. Development and validation of an urban street canyon model based on carbon monoxide experimental data measured in Firenze. Urban Transport and the Environment for the 2lst Century, Editor L.J. Sucharov, Computational Mechanics Publications, Southampton, U.K.

Theodoridis G., Karagiannis V., Valougeorgis D., 2001. Numerical predictions of dispersion characteristics in an urban area based on advanced high Reynolds turbulence models. 3rd International Conference on Urban Air Quality, Loutraki, Greece. 
Theodoridis G., Moussiopoulos N., 2000. Influence of building density and roof shape on the wind and dispersion characteristics in an urban area: a numerical study. Environmental Monitoring and Assessment 65, 407-415.

Theurer W.. 1999. Typical building arrangements for urban air pollution modelling. Atmospheric Environment 33, 40574066.

Tokyo Metropolitan Government, 1983. Study on the air quality models for the prediction on the vicinity of streets. Tokyo Metropolitan Government, Environmental Protection Bureau (in Japanese).

Turner D.B., 1970. Workbook of atmospheric dispersion estimates. Cincinnati, Ohio. U.S. Department of Health, Education, and Welfare. Environmental Health Service.

Uehara K., Murakami S., Oikawa S., Wakamatsu S., 2000. Wind tunnel experiments on how thermal stratification affects flow in and above urban street canyons. Atmospheric Environment 34, 1553-1562.

Vachon G.. Louka P., Rosant J-M., Mestayer P., Sini J-F., 2001. Measurements of traffic-induced turbulence within a street canyon during the Nantes'99 experiment. 3rd International Conference on Urban Air Quality, Loutraki, Greece.

Vachon G.. Rosant J-M., Mestayer P., Louka P., Sini J-F., Delaunay D., Antoine M-J., Ducroz F., Garreau J., Griffiths R., Jones C.. Lorin Y., Molle F., Peneau J-P., Tetard Y., Violleau M., 2000. Experimental investigation of pollutant dispersion within a street in a low wind conditions, the experiment Nantes'99. 9th International Symposium "Transport and Air Pollution", Avignon, France. INRETS, 95-102.

Väkevä M.. Hämeri K., Kulmala M., Lahdes R., Ruuskanen J., Laitinen T., 1999. Street level versus rooftop concentrations of submicron aerosol particles and gaseous pollutants in an urban street canyon. Atmospheric Environment 33, 1385-1397.

van den Hout K.D. Baars H.P., Duijm N.J., 1994. Effects of buildings and trees on air pollution by road traffic. Proceedings of the 8th World Clean Air Congress, Vol. 4, Elsevier, Amsterdam.

Vardoulakis S.. Fisher B.E.A, Gonzalez-Flesca N., Pericleous K., 2002b. Model sensitivity and uncertainty analysis using roadside air quality measurements. Atmospheric Environment (in press).

Vardoulakis S.. Gonzalez-Flesca N., Fisher B.E.A., 2000. Air quality monitoring and modelling techniques for street canyons: the Paris experience. 8th International Conference on Air Pollution, Cambridge, UK, WIT Press, 505-513.

Vardoulakis S.. Gonzalez-Flesca N., Fisher B.E.A., 2002a. Assessment of traffic-related air pollution in two street canyons in Paris: Implications for exposure studies. Atmospheric Environment 36, 1025-1039.

Venegas L.E.. Mazzeo N.A., 2000. Carbon monoxide concentration in a street canyon of Buenos Aires city (Argentina). Environmental Monitoring and Assessment 65, 417-424.

Venetsanos A.G.. Bartzis J.G.. Andronopoulos S., Vlachogiannis D., 2001. Vehicle effects on street canyon air pollution pattern. 9th International Conference on Modelling, Monitoring and Management of Air Pollution, Ancona, Italy, WIT Press, 193-202.

Versteeg H.K.. Malalasekera W., 1995. An introduction to computational fluid dynamics - The finite volume method. Longman Scientific \& Technical.

Vignati E., Betkowicz R., Hertel O., 1996. Comparison of air quality in streets of Copenhagen and Milan, in view of the climatological conditions. The Science of the Total Environment 189/190, 467-473.

Vignati E., Berkowicz R., Palmgren F., Lyck E., Hummelshoj P., 1999. Transformation of size distributions of emitted particles in streets. The Science of the Total Environment 235, 37-49.

Wåhlin P., Palingren F., Van Dingenen R., 2001. Experimental studies of ultrafine particles in streets and the relationship to traffic. Atmospheric Environment 35, S63-S69.

WHO. 2000. Air quality guidelines for Europe. Copenhagen, Denmark

Wright E.. 2001. Results from the EU LIFE RESOLUTION project. International Conference Measuring Air Pollutants by Diffusive Sampling, Montpellier, France.

Xia J., Leung D.Y.C., 200 la. Pollutant dispersion in urban street canopies. Atmospheric Environment 35, $2033-2043$.

Xia J., Leung D.Y.C., 2001b. A concentration correction scheme for Lagrangian particle model and its application in street canyon air dispersion modelling. Atmospheric Environment 35, 5779-5788.

Yamartino R.J.. Wiegand G., 1986. Development and evaluation of simple models for the flow, turbulence and pollutant concentration fields within an urban street canyon. Atmospheric Environment 20, 2137-2156.

Yoshikawa Y.. Kunimi H., 1998. Numerical simulation model for predicting air quality along urban main roads: First report, development of atmospheric diffusion model. Heat Transfer-Japanese Research 27 (7), 483-496.

Zachariadis T. Samaras Z., 1999. An integrated modelling system for the estimation of motor vehicle emissions. J. Air and Waste Management Association 49, 1010-1026.

Zametti P., 1990. Air Pollution Modeling: theories, computational methods, and available software. Southampton, U.K.

Zoumakis N.M., 1995. A note on average vertical profiles of vehicular pollutant concentrations in urban street canyons. Atmospheric Environment 29 (24), 3719-3725. 


\section{Captions}

Table 1: Classification of commonly used dispersion models.

Figure 1: Pollutant dispersion in a regular street canyon (Dabberdt et al., 1973).

Figure 2: Perpendicular flow regimes in urban canyons for different aspect ratios (Oke, 1988).

Figure 3: (a) Flow field within and above a wide street canyon as it was reproduced using CHENSI, and (b) vertical profiles of the normalised horizontal wind component $\left(u / U_{r u f}\right)$ measured in a wind tunnel (BLASIUS) and predicted using five different CFD models. $H$ and $W$ are the height and the width of the canyon, and $z$ and $x$ the height and the distance of the receptor from the canyon wall, respectively (Sahm et al., 2001).

Figure 4: STREET-SRI, OSPM and AEOLIUS predictions against (a) roadside CO (ppm) measurements obtained with a standard infrared analyser and (b) benzene ( $\mathrm{ppb}$ ) measurements obtained with passive samplers at different locations in Rue de Rennes, Paris (Vardoulakis et al., 2002a). 


\section{Table 1}

\begin{tabular}{|c|c|c|c|c|c|c|c|c|}
\hline \multicolumn{6}{|c|}{ Parametric } & \multicolumn{3}{|c|}{ Numerical } \\
\hline \multicolumn{2}{|l|}{ Empirical } & \multicolumn{4}{|c|}{ Semi-empirical } & \multicolumn{2}{|c|}{ Eulerian } & \multirow{2}{*}{$\begin{array}{c}\text { Lagrangian } \\
\text { Stochastic particle }\end{array}$} \\
\hline Statistical & Receptor & Screening & Box & Street canyon & Gaussian & Microscale (CFD) & Urban scale & \\
\hline Derwent and & COPREM & CAR International & STREET-SRI & CPBM & ADMS-Urban & PHOENICS & MEMO & GEM \\
\hline Middleton (1996) & Karim and & AEOLUS Screen & MAPS & OSPM & INDIC AIRVIRO & FLUENT & METRAS & Addison et al. (2000) \\
\hline \multirow[t]{10}{*}{ Stedman et al. (2001) } & Ohno (2000) & AEOLIUSQ & STREET BOX & AEOLIUS & TNO-Traffic & STAR-CD & CALGRID & Jicha et al. (2000) \\
\hline & & STREET & Nicholson (1975) & SLAQ & CAR-FMI & CFX-TASCflow & & Xia and Leung \\
\hline & & UK DMRB & & OMG & PROKAS-V & PANACHE & & $(2001 a, b)$ \\
\hline & & & & Hotchkiss and & HIWAY-2 & MERCURE & & \\
\hline & & & & Harlowe (1973) & CALINE4 & CHENSI & & \\
\hline & & & & & APRAC & MISKAM & & \\
\hline & & & & & PUFFER & MIMO & & \\
\hline & & & & & & MITRAS & & \\
\hline & & & & & & ADREA-HF & & \\
\hline & & & & & & FloVENT & & \\
\hline
\end{tabular}




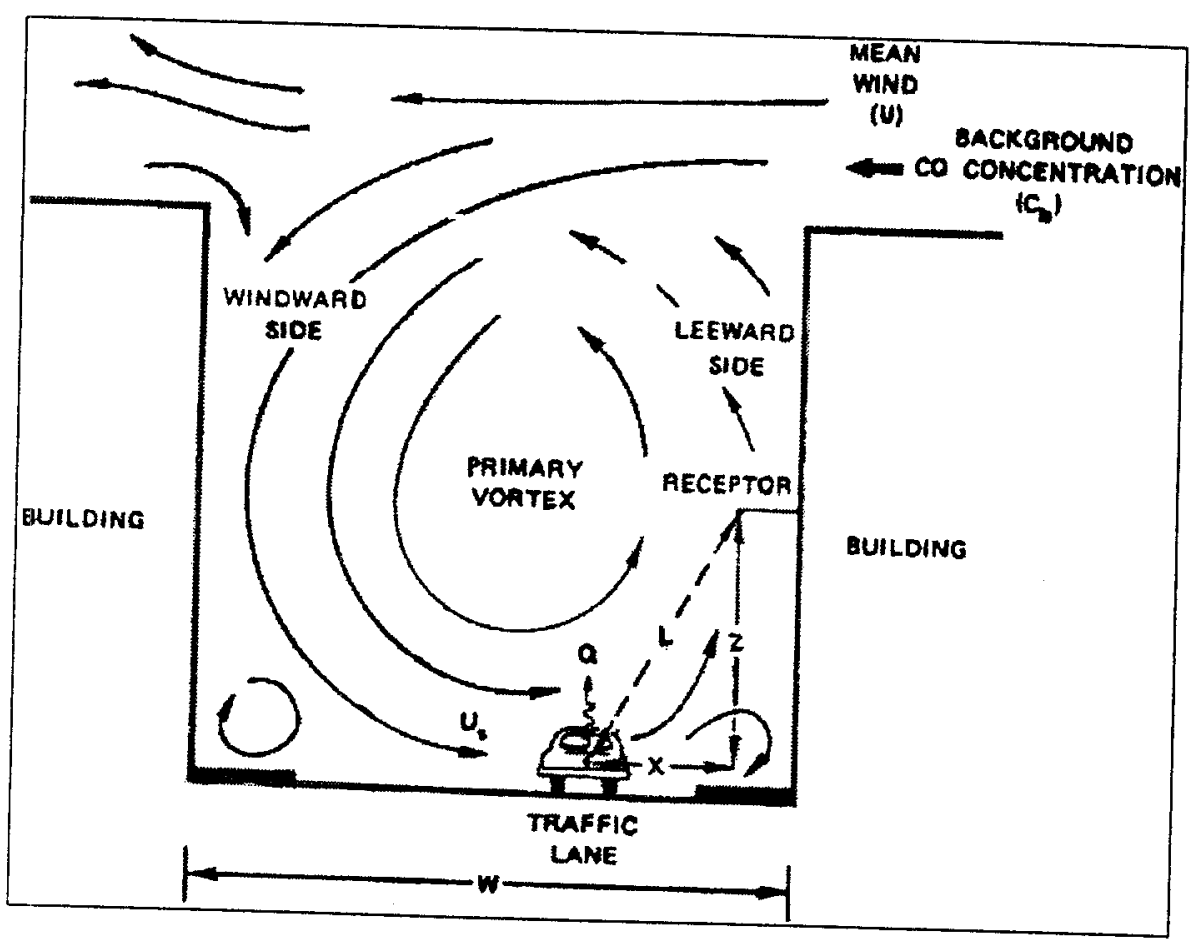

Fig. 1 


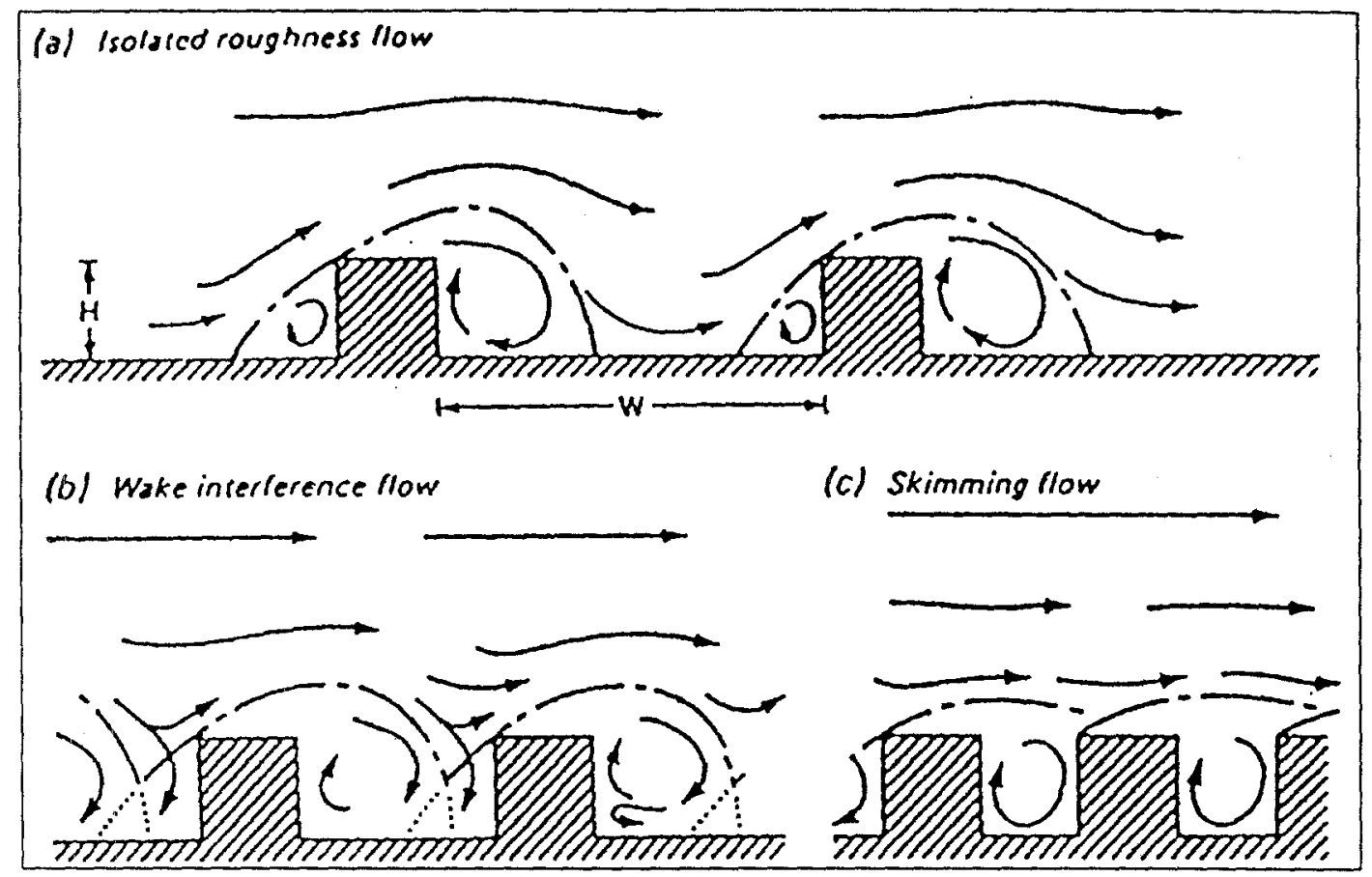

Fig. 2 


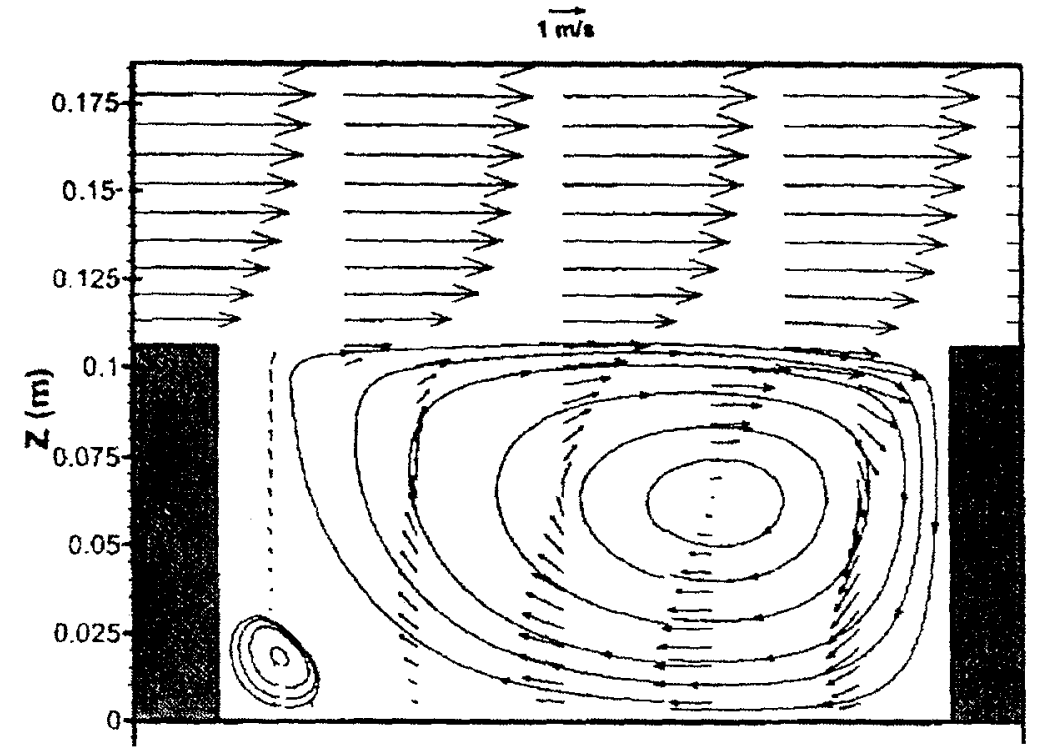

Fig. 3a
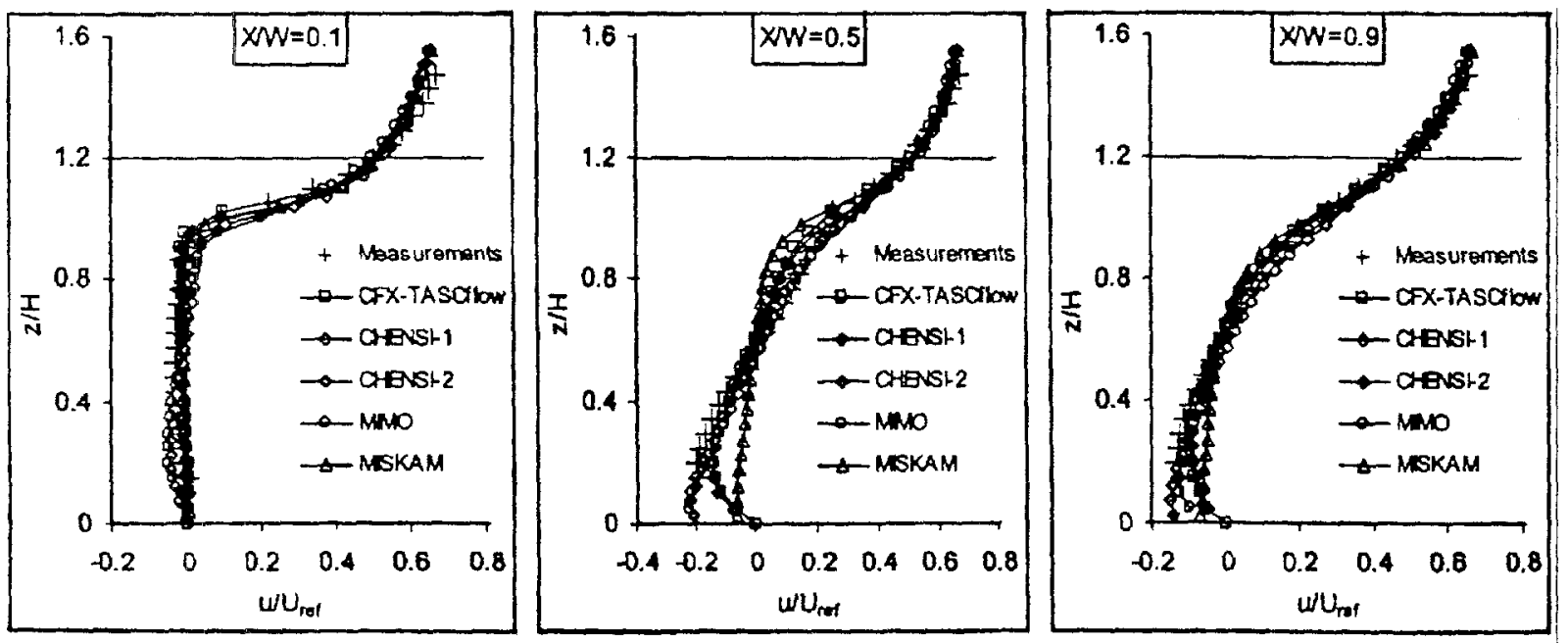

Fig. 3b 
Rue de Rennes (Paris)

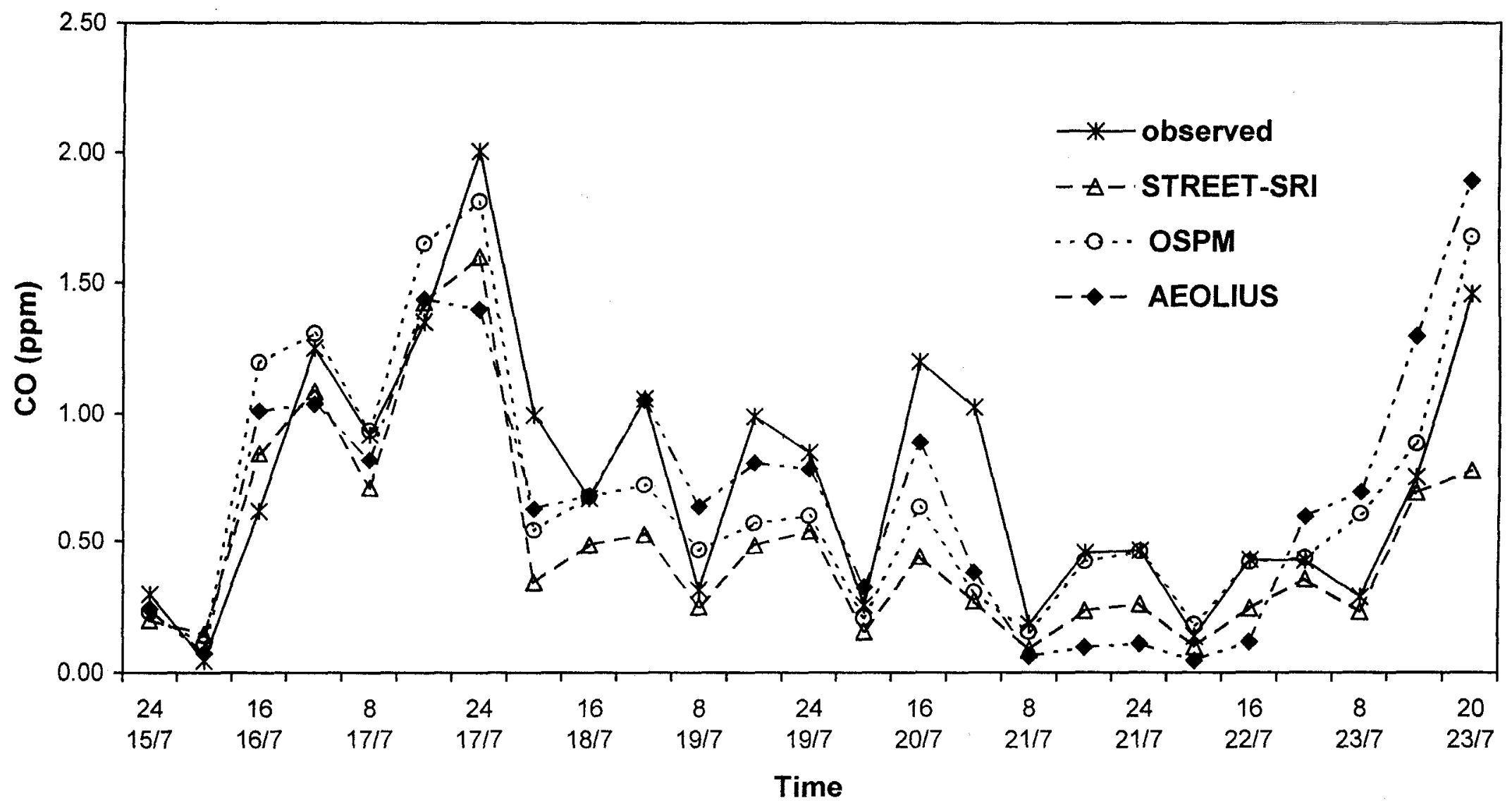

Fig. 4a 
Rue de Rennes (Paris)

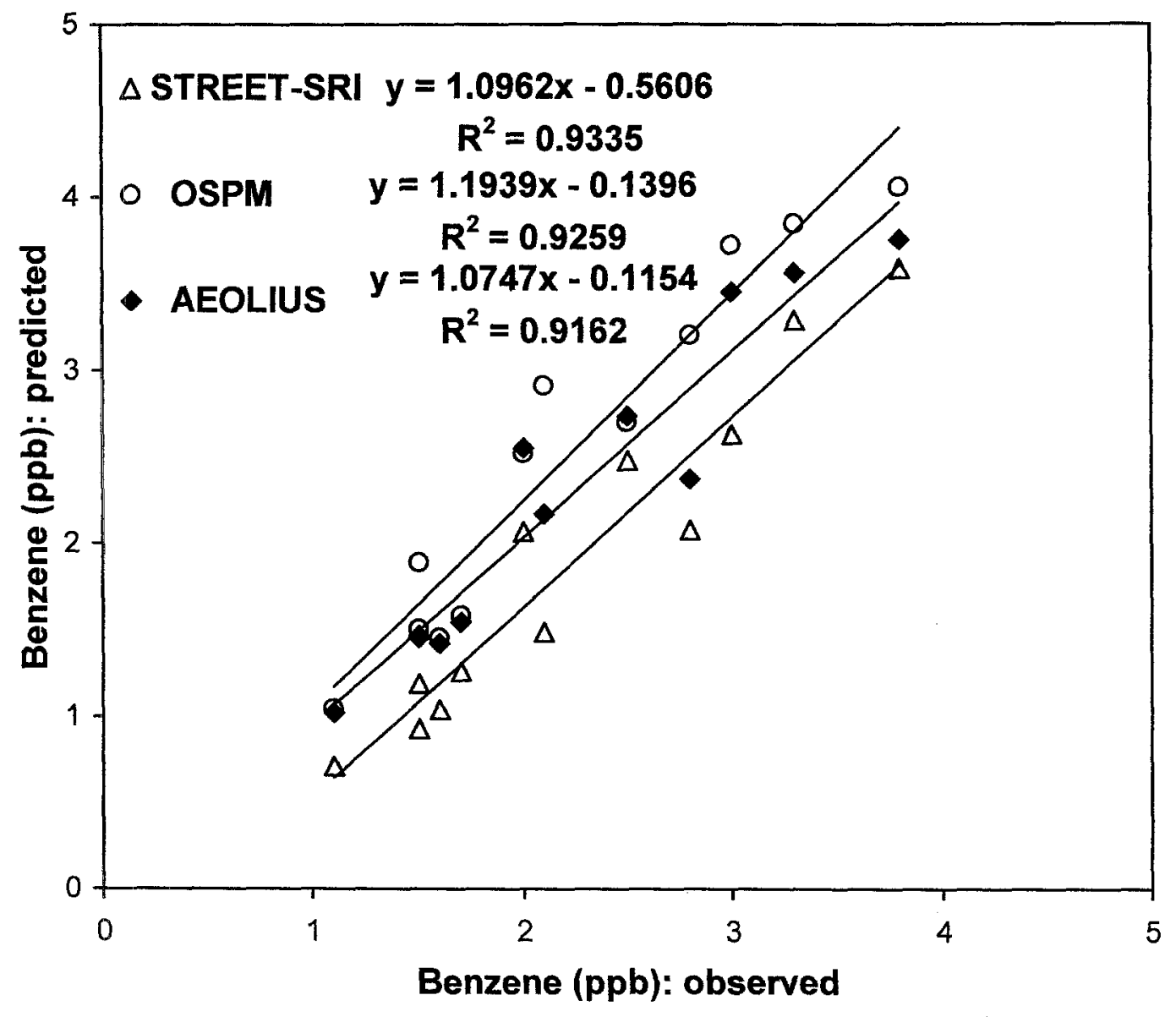

Fig. 4b 